\title{
Chapter 1 \\ Introduction to Recent Advances in Quality Assessment for Adhesive Bonding Technology
}

\author{
Michael Noeske, Welchy Leite Cavalcanti, Hauke Brüning, Bernd Mayer, \\ Antonios Stamopoulos, Apostolos Chamos, Thomas Krousarlis, \\ Paweł H. Malinowski, Wiesław M. Ostachowicz, Konstantinos Tserpes, \\ Kai Brune, and Romain Ecault
}

\begin{abstract}
The first chapter highlights the relevance of both adhesive bonding technology and in-process quality assessment for mastering twenty-first-century challenges in joining functional and lightweight materials like carbon fibre reinforced polymers. The ongoing developments of the relevant technological and regulatory procedures and frameworks are hereby outlined, following trends for datadriven innovation and standardisation. Advances from monitoring process variables towards the in-depth and objective Extended Non-destructive Testing (ENDT) of material-related features are presented, based on methodological and technological innovation and insights from recent European joint research projects like Horizon 2020s ComBoNDT - “Quality assurance concepts for adhesive bonding of aircraft composite structures by advanced NDT”. Introducing ten heuristic principles for quality assessment in bonding processes, a concept is demonstrated for establishing empirically consolidated sets of quantitative material and process-specific correlations between design-relevant joint features and quality data measured during the manufacture or repair of adhesive joints using ENDT. Each correlation is obtained by systematically introducing disturbances of relevant process features identified by experts and is levelled once by linking findings from standardised mechanical tests
\end{abstract}

M. Noeske $(\varangle) \cdot$ W. Leite Cavalcanti $\cdot$ H. Brüning $\cdot$ B. Mayer $\cdot$ K. Brune

Fraunhofer Institute for Manufacturing Technology and Advanced Materials IFAM, Wiener Str.

12, 28359 Bremen, Germany

e-mail: michael.noeske@ifam.fraunhofer.de

A. Stamopoulos · A. Chamos · T. Krousarlis

EASN Technology Innovation Services, Terweidenstraat 28, 3440 Budingen, Belgium

P. H. Malinowski · W. M. Ostachowicz

Institute of Fluid-Flow Machinery, Polish Academy of Sciences, Fiszera 14, Gdańsk 80231,

Poland

K. Tserpes

Laboratory of Technology \& Strength of Materials, Department of Mechanical Engineering \&

Aeronautics, University of Patras, 26500 Patras, Greece

R. Ecault

Airbus Operations S.A.S., 316, Route de Bayonne, B.P. D4101, 31060 Cedex 9 Toulouse, France

W. Leite Cavalcanti et al. (eds.), Adhesive Bonding of Aircraft Composite Structures, https://doi.org/10.1007/978-3-319-92810-4_1 
with ENDT results obtained for joints that have intentionally been manufactured or repaired in an off-specification way. Subsequent chapters will demonstrate the suitability of the broadly applicable process.

Keywords Adhesive bonding technology $\cdot$ Quality assessment $\cdot$ In-process data $\cdot$ Extended non-destructive testing $($ ENDT) $\cdot$ Heuristic principles $\cdot$ Concepts from ComBoNDT project

\subsection{Introduction}

Adhesive bonding was already being applied more than 35,000 years ago in the Upper Palaeolithic in the Near East using naturally occurring bitumen [1] as well as in Europe during the contemporaneous last Ice Age [2] and starting from the Middle Palaeolithic to the Iron Age using wood or birch-bark tar [3, 4]. Adhesive joints based on biomaterials are also known from the Swabian Aurignacian [5] in the Upper Palaeolithic. For example, hollowed-out adherends consisting of flint and split animal bones or mammoth teeth were re-joined and re-sealed using an airtight resin glue (an organic mastic that was possibly birch tar obtained using fire [6]) to manufacture a single piece of work that contributed to the social cohesion inside fireheated caves inhibited by modern humans or even Neanderthals. These joints created musical instruments, highlights of humanity's cultural repertoire, and their product quality was tested by the musicians and their audience. As early as the Neolithic, inorganic sandwich composite adhesives consisting of fillers and binders were used to manufacture poly-layered joints as ornamental artefacts [7]. In the Taklamakan Desert in north-western China, early evidence of adhesives and their development around 3500 years ago was recently collected in the form of a bone sculpture-inlaid wooden artefact [8]. The development of adhesives and bonding applications was further advanced in ancient Greece and the Roman Empire [9]. In fact, throughout human history, adhesives have been among the most widely applied materials [8] and their use was one of the earliest known transformative technologies [10], yet many of these historical advances have only recently been revealed through archaeological excavations and investigations.

In Europe, the modern era was initiated by the re-discovery of Greek and Roman cultural and knowledge heritage, triggering the three Industrial Revolutions, which facilitated machine-driven mass customisation and computer-driven digital data processing. The fourth Industrial Revolution is currently ongoing, encompassing exchangeable decentralised datasets and individualised information available anytime and anywhere and joining the biological, physical, and digital fields to form cyber-physical systems. The advent of Industry 4.0 is updated music to the audience's ears-be it students or professionals, engineers or natural scientists, and it will connect more than seven billion humans worldwide. Such extensive communication will be based on documenting and preserving, sharing and highspeed exchanging trackable digital data or even knowledge, a development that is 
entering site-comprehensive production chains step by step. This advancement also challenges modern adhesive bonding for the series production of multifunctional materials for the simple reason that quality assessment and quality management in production technologies are not based on archaeological methods or tools. Nonetheless, we suggest that making relevant material-based aspects accessible is a crucial endeavour, both in archaeology and in forward-looking production technologies, and that this perspective will spawn the analysis of augmentable domain-specific data sources that are virtually unbounded in both cases.

We consider modern tools for quality assessment in adhesive bonding technology worth the readers' attention, and we present recent progress in the research, development and application of process-integrated monitoring technologies for joining composite structures. We systematically introduce our readers to extended nondestructive testing (ENDT) and provide a compendium for quality or process engineers throughout their professional lives as well as for students as an applicationoriented introduction to the interdisciplinary topics at hand, comprising physicochemical, material and process engineering aspects.

In this section, we give a short introduction to ENDT and quality assessment in adhesive bonding processes relevant to the manufacture or repair of composite structures.

Why are these topics so highly relevant at present? Fundamentally, we share expectations that in the twenty-first century, progress in joining functional or lightweight materials and components will essentially be driven by innovations based on adhesive bonding technology and by developments that will enable manufacturers to safeguard the quality and optimise production [11-13], integrating these three drivers into a factory-of-the-future approach for composite manufacture, e.g. in the aerospace or automotive industries [14-16]. With the aim of achieving cost efficiency and increased flexibility with many degrees of freedom [17, 18], computer-integrated manufacturing will be established for all process steps, including those related to adhesive bonding. In this way, the increasing market demand for new and highly customised products with high quality [19] will be met and a small time-to-market delay will be achieved. In view of challenges like shorter response opportunities and flexibility in a turbulent and unpredictable market environment while preserving product quality [19], knowledge capturing and processing profiting from formal methods, e.g. taxonomies and ontologies [20], are gaining importance and may greatly contribute to rule-driven manufacturing control [21]. In addition to the software and information technology infrastructure presently being developed, hardware that facilitates the gathering of precise in-process data from all process steps will be needed as a third pillar $[18,22,23]$ within less than a decade. These intelligent hardware elements of machines and devices such as sensors and actuators contribute to the "field-level" base of the industrial automation pyramid [19, 24], which highlights the numerous components and pathways of industrial communications, as sketched in Fig. 1.1. Within an automation pyramid, the upper levels are characterised by a deeper understanding and a higher responsibility for the performance of the complete overall system. The deeper levels within the hierarchy are distinguished by increasingly detailed knowledge about individual processes and process steps or 


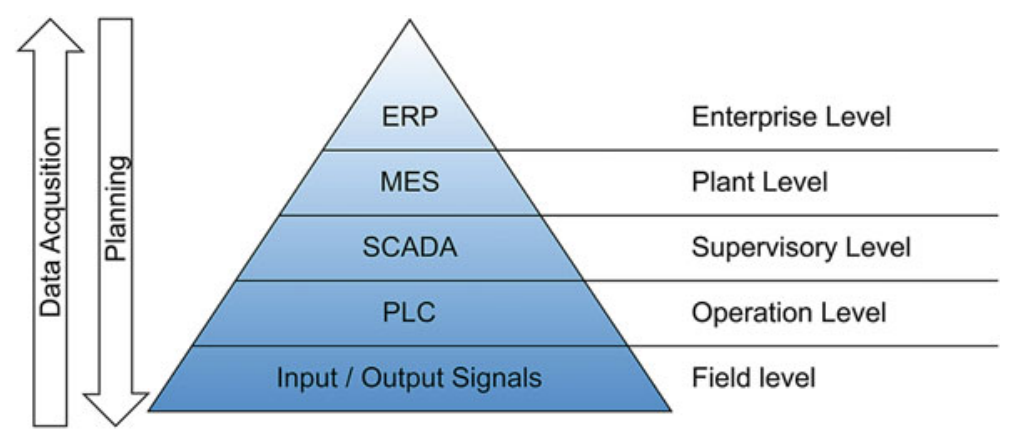

Fig. 1.1 Hierarchical model of an industrial automation pyramid based on field-level sensing. The first level or "field level" comprises the physical devices such as actuators and sensors. The second level or "operation level" includes logical devices such as Programmable Logic Controllers (PLC) or PCs usually found in complex machinery. The "supervisory level" (third level) corresponds to the supervisory control and data acquisition systems (SCADA) used to monitor and operate individual processes. The manufacturing execution systems (MES) are responsible at a higher "plant level". The top of the pyramid ("enterprise level") comprises the company's integrated management system (ERP) controlling the company's global operations. Providing, implementing and evaluating hardware that enables precise in-process data to be gathered within a comprehensive concept for quality assurance is a key target of the present book

technologies. In matters of smart manufacturing knowledge management, the basic data form the foundation for the higher levels, which are targeted towards manufacturing information, scientific understanding (e.g. providing predictive models), and knowledge [25]. In the future, for some systems, e.g. for monitoring bonded repair of composite aircraft structures, highest level standalone and autonomous opportunities appear accomplishable from a scientific point of view [26].

Bearing these expectations and challenges, but also the self-limiting frame of this book, in mind, we will introduce one comprehensive concept, ten pathbreaking heuristic principles, and more than a dozen tools which are accessible for interoperability and facilitate implementing and operating a quality assessment (QA) system. These form a profound base for quality assurance within a superordinate and nevertheless interlinked quality management system. We expect that sensing systems comprising ENDT tools and concepts [27, 28] as well as sensors and sensor concepts [18] will thus provide a solid foundation both for this approach following Industry 4.0 and for quality assessment as a technical pre-requisite for quality assurance.

\subsection{Technological and Regulatory Framework}

In this section, we will introduce a succinct description of adhesive bonding processes and render some aspects of quality assurance and monitoring before describing the ongoing advancement of quality assessment with a focus on adhesive bonding processes. After detailing ten heuristic principles for quality assessment, we will 
integrate methods and tools for ENDT. Finally, we will present a concept for ENDT and quality assessment in adhesive bonding, which will then be further elaborated in the subsequent chapters of this book.

\subsubsection{Adhesive Bonding Processes}

The track record and success story of adhesive bonding technology are based on establishing and safeguarding reliable joining processes. The early one and a half decades of the twenty-first century highlighted that quality assurance "for correct adhesive application and documented via certification" contributes to minimising faults, saving money, generating trust, promoting the wider use of adhesives, and sustainably improving the image of adhesive bonding, which may be clouded by observations that "bonding errors are often still encountered" [11]. So, let us first and foremost grasp a clearly arranged and predominantly technical image of this promising joining technology.

According to DIN EN 923, adhesives are non-metallic substances capable of joining materials through surface bonding (adhesion), with the bond possessing adequate internal strength (cohesion) [9]. The result of applying bonding as a material joining technique, i.e. the product of the bonding process, is an adhesive joint. Concerning the feasible lifecycle of an adhesive joint, such a bonding process may occur during manufacture [12] or during repair [29].

Characteristically, an adhesive bonding process may be divided into consecutive phases of the preparation of the constituent materials (such as adherends, [optionally] prepregs and the adhesive system comprising [optionally] primers and the adhesive), the application of the adhesive system, the assembly/lay-up, the curing and the final finishing. Each of these phases may be subdivided into further steps and finally strung together to form the process chain [30].

In the framework of these technical processes (or process chains), the adherend and adhesive materials may be described as operands, i.e. objects with initial relevant properties that are changed by the effect of one or more factors [31]. Following a procedure presented by Mattmann [31] for describing a product lifecycle, these factors are provided by technical systems denoted as operators. Correspondingly, at the end of a bonding process, the final state of the operands is different from the initial state, with the difference being described by the new, process-induced properties. In most cases, the bonding process is a successive multi-step process which may be described as a process chain with a chronologically defined sequence of process steps grouped in process phases [30]. Other operands in addition to the adherends and the adhesive will often need to be considered, e.g. in the case of a multi-layer adhesive system.

Therefore, in a short formal description consistent with Mattmann's approach [31], we suggest the diction for the adhesive bonding process as comprising the time-dependent (state and property) transformation $\mathrm{T}(\mathrm{t})$ of several operands starting from an (overall) initial state $S_{i}\left(t_{0}\right)$ prevailing at the onset of the process at the point 
in time $t_{0}$. When the process is completed at time $t_{f}$, a final state $S_{f}\left(t_{f}\right)$ is achieved. As expressed by Eq. (1.1), the states $S_{i}\left(t_{0}\right)$ and $S_{f}\left(t_{f}\right)$ are described by property vectors at the defined points in time $t_{0}$ and $t_{f}$, and the achieved change and difference resulting from the process. Within a process chain, the operand is unequivocally described by the entity of its properties (in three spatial dimensions) at any time (as the fourth dimension) for all consequentially feasible intermediate process states.

$$
\mathrm{S}_{\mathrm{f}}\left(\mathrm{t}_{\mathrm{f}}\right)=\mathrm{T}\left(\mathrm{t}_{\mathrm{f}}\right) \bullet \mathrm{S}_{\mathrm{i}}\left(\mathrm{t}_{0}\right)
$$

In a technical engineering approximation highlighted by Eq. (1.2), among the operand properties, process-relevant time-dependent features, such as $\mathrm{s}_{\mathrm{A}}\left(\mathrm{t}_{1}\right)$ and $\mathrm{s}_{\mathrm{B}}\left(\mathrm{t}_{1}\right)$, may be identified based on the requirements to be met. Thus, the related feature vector $S\left(t_{1}\right)$ is a quantitative descriptor for the prevailing state of the operands as governed by the effect of the, respectively, performed set of operations, represented by the transformation $T\left(t_{1}\right)$, having been executed for (i.e. until) the point in time $t_{1}$.

$$
\mathrm{S}\left(\mathrm{t}_{1}\right)=\left(\mathrm{s}_{\mathrm{A}}\left(\mathrm{t}_{1}\right), \mathrm{s}_{\mathrm{B}}\left(\mathrm{t}_{1}\right), \ldots\right)
$$

Subsequently, the initial and final states of the operands will be technically described by the feature vectors $S\left(t_{0}\right)$ and $S\left(t_{f}\right)$, respectively. Clearly, the complete description of these states using the respective property vectors may comprise additional properties which are not significantly modified during the course of the adhesive bonding process. In this way, the pursued concept for systemically approaching the features will determine the accuracy of this approximation, which in practice will crucially depend on the iteratively achieved process and material know-how.

In a nutshell, following this diction the adhesive bonding process is described by the time-dependent procedure and changes of both the operator and operand states, as highlighted in Fig. 1.2. In more detail, when implementing such process representation as described by Eq. (1.1), the estimated operator-operand interactions may either be neglected, i.e. considered small as compared to the main effects of the operations affecting the operators or the operands, or they may be included in the concept of the operator or operand.

Visualising the first approach, a process in a controlled environment-with small and controlled deviations from a known and understood procedure described by $(\mathrm{T}+\Delta \mathrm{T})(\mathrm{t}) \bullet\left(\mathrm{S}_{\mathrm{i}}+\Delta \mathrm{S}_{\mathrm{i}}\right)$-may be assessed based on the knowledge of the main effects in the "reference" process, e.g. a qualified process. As a first example, in a wet cleaning step, the accumulation of known auxiliary materials of preceding process steps within the cleaning bath is maintained within evaluated parameter intervals $[(\mathrm{T}-\Delta \mathrm{T})(\mathrm{t}),(\mathrm{T}+\Delta \mathrm{T})(\mathrm{t})]$ through the tailored measures of the process control. As a second example, identifying a deviation of the adherend surface cleanliness exceeding the evaluated parameter interval $\left[\left(S_{i}-\Delta S_{i}\right),\left(S_{i}+\Delta S_{i}\right)\right]$ may result in deciding to perform a further, e.g. repeated, cleaning step rather than deciding to, e.g. change the adhesive system of the following bonding steps.

Visualising the second approach, the material-dependent effects of processes may be attributed to respective material features in a material-specific process described 

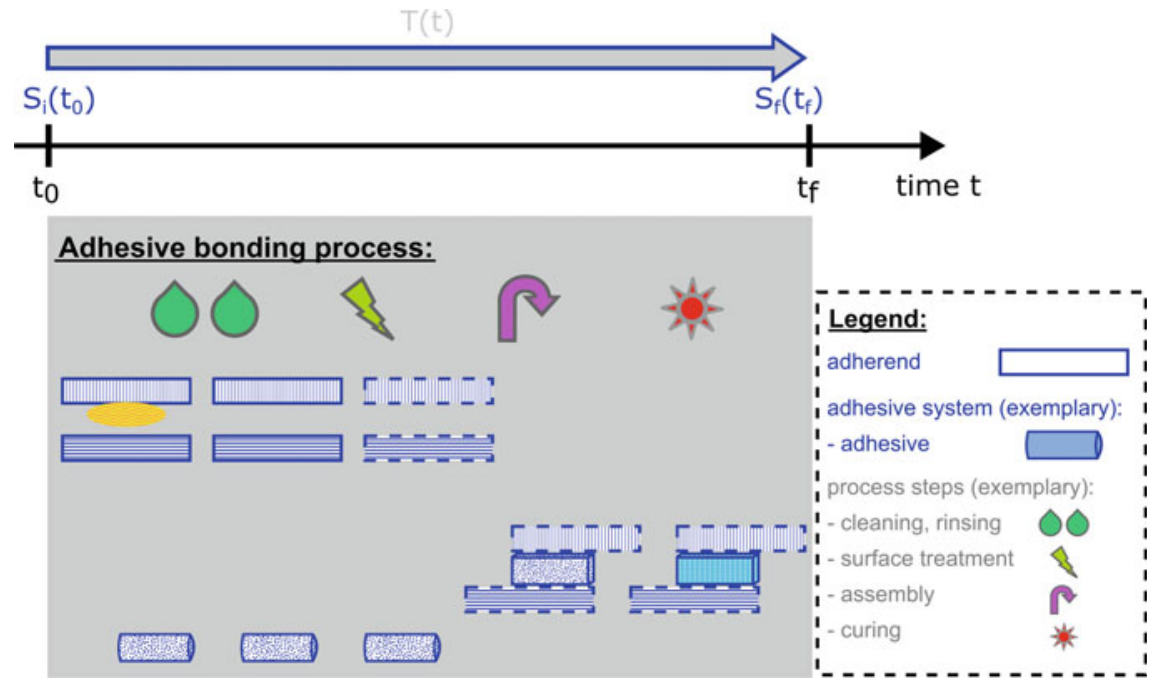

Fig. 1.2 An example of a process chain in adhesive bonding, with operands (with a blue outline) being successively changed through a time-dependent transformation $T(t)$ from an initial state $S_{i}\left(t_{0}\right)$ to a final state $S_{f}\left(t_{f}\right)$ due to the effects of the operators (with a grey outline). In this example, the top adherend is partially covered by contamination (shown in yellow) at the beginning of the bonding process

by $\mathrm{T}\left(\mathrm{t}, \mathrm{S}_{\mathrm{i}}\right)$, i.e. promptly adapting the operator action following the detection of deviations from an "expected" initial operand state. For instance, in the curing oven of an adhesive bonding process, the temperature reached by the pre-connected adhesive system and adherends within a given time may be consciously adjusted following the heat capacity and heat conductivity of the involved materials and devices. Therefore, using different operands will mean applying a different, "new" process tailored to the materials and the geometry of the joint to be manufactured.

From our point of view and following the perception highlighted in Fig. 1.1, technically facilitating the first approach is currently feasible and in the near future will increasingly be substantiated based on access to manufacturing information. We expect that the second approach will require a more profound understanding, which will prospectively be provided by longer term information-related data evaluation.

When geometrically extended specimens or even devices are to be adhesively bonded, the comprehensive prevailing feature vector $S\left(t_{1}\right)$ may be complex and comprise regions of the devices which are insignificantly affected by the considered bonding process. In such cases, a reduction of the topological complexity of the respective process description may be necessary and can be achieved by predominantly embracing the relevant conformational elements, e.g. those characterising the design regions comprising the bonding areas of the adherends. As adhesive bonding is based on adhesion, the feature vector describing the operands "adherend1" and "adherend2" shall necessarily comprise the surface properties of these solids in 
the bonding region. Meanwhile, the time-dependent feature vector describing the adhesive system shall comprise the interaction with the adherend surfaces.

In the following sections, we will demonstrate the application of these aspects for a described bonding process.

\subsubsection{Quality Assurance and Monitoring}

According to a strict definition, quality is first and foremost the compliance of services with the requirements. These requirements can be created by customers, manufacturers or users, but also by the services themselves. Briefly, with respect to competitiveness, an essential aspect of quality is "the elimination of waste" [32].

However, there is also a far-reaching aspect behind the term quality, one which is often associated with product safety and by extension, for example, the financial success of a company. The reliability of a product can often only be achieved through good quality. Moreover, high-quality products provide the basis for manufacturing in the high-wage countries of the EU, as these reach higher market prices. Nevertheless, quality control is a challenge for many manufacturing companies. House-made standards and testing standards usually help to achieve internal quality goals, but in order to demonstrate quality to external customers, it is often necessary to refer to norms and known standards or even be certified according to a recognised standard. Therefore, proof of compliance with a standard is provided by a certification process, followed by the issuance of a temporary certificate by independent certification bodies. One of the best-known quality standards is ISO 9001, which specifies a quality management system that an organisation (e.g. in the frame of a manufacturing process) must meet in order to comply with the quality requirements. Among other aspects, it introduces the concept of the so-called "special process", which is a process "in which the result cannot be fully verified (checked) by subsequent monitoring and measurement or non-destructive testing of the product" [33]. This includes processes such as welding or bonding. With these "special processes", a strategy for avoiding errors must be developed through a complete planning of the process, whereby all error-influencing factors must be identified and defined. In the production phase, all parameters must be checked and finally documented for the feasibility of the considered process. Even if this standard only defines the minimum requirements for a quality management system, the basic idea is ingenious. Secured processes prevent errors at specific points in the process, and over the entirety of the individual secured process steps, the quality of a product is controlled [34]. An example detailed by Espie et al. [32] highlights that "adhesive bonding can be a more complex procedure to control than other joining methods", demonstrated by the fact that "on a car assembly line spot welding is the responsibility of one station, but up to five points of the line can contribute to success or failure of a bonded joint". This indicates of course that the basic idea of ISO 9001 must be put into practice in a technology-specific way, since it is very general and the quality management system only conducts specific checks. It does not contain any further information on specific 
application techniques such as joining technology, e.g. bonding. Based on the core idea of ISO 9001, standards such as DIN 2304 [35] apply and specify the requirements in a technology-specific manner. DIN 2304-1 specifies requirements for the quality-assured execution of structural, i.e. load-carrying, adhesive bonds along the process chain of bonding - from development to manufacture and repair-and thus provides a basic framework for achieving high-quality bonded products.

Quality management thus comprises the product which the customer is buying, the process to manufacture or deliver this product, and the organisational system behind it [32]. Aiming at effectively implementing the continuous improvement of the product, the process and the system, the monitoring of events is desirable in addition to establishing a controlled environment [32]. Perceived as a tool, "the essence of monitoring is to look at trends and changes (or the lack of them) over time to reveal actions necessary to be taken with processes and the system, or to confirm that all is well" [32].

One immediate effect of monitoring in the age of digitalisation is that data are not only measured but also stored in great quantities, making them accessible for extensive evaluation and analysis [23]. Formally, the acquired data contribute to a complex materials characterisation data space. The precise format and architecture of such data are subject to ongoing research and industrial initiatives, e.g. considering concerted taxonomies and ontologies for contextual data. For example, Allotrope Foundation, founded in 2012, "is developing advanced data architecture to transform the acquisition, exchange, and management of laboratory data throughout its complete lifecycle" [36]. Within the Allotrope Taxonomies Domain Model, an entity of data is composed of the five domains of material (e.g. sample), equipment (e.g. spectrometer), process (e.g. method), result (e.g. spectrum) and property (of the data type or object). A similar approach for laboratory data appears feasible for structuring in-process monitoring data. Indeed, for the evaluation of monitoring data as a tool of quality control, mathematical, e.g. statistical, approaches are currently being discussed in the literature, which deals in-depth with structuring, e.g. clustering, the data and identifying their relevance to the quality of a manufactured product. Some key aspects are the following:

- Monitored data, i.e. the data vector or matrix obtained, may include on the one hand measurements of process variables related to the manufacturing process (and formally $\mathbf{T}\left(\mathrm{t}_{1}\right)$ ), and on the other hand measurements of quality variables related to the manufactured product (and formally $S\left(t_{1}\right)$ ) [37, 38]. For example, statistical process monitoring (SPM) is based on both process variables and quality variables, while the focus of multivariate statistical quality control (MSQC) literature is on the monitoring of quality variables [37]. As highlighted above, the measurement process itself also consistently requires process monitoring and documentation.

- Process variables are often measured frequently and come in large quantities, while quality variables are measured at much lower rates and often come with a significant time delay [37].

- Root causes of potential quality problems may sometimes be related to a set of certain process variables [37], which is why two [39] or more [40] sub-blocks 
for process data have been suggested, depending on their correlation with quality variables which are characterised by, e.g. mutual information (MI) values [39].

- Smart manufacturing which links physical and cyber capabilities will profit from managing large amounts of information and will facilitate improved diagnostics and prognostics, e.g. for fault detection or predictive maintenance [41]. Manufacturing operations and product quality may be improved by implementing process analytics delivering high-quality data and by "incorporating subject matter expertise in solution design" [41]. Combining such domain knowledge like subject matter expertise in analytics with the process and material expertise appears especially relevant to approaching the relationship and possibly the correlation between the measured data vector and the material feature vector $S\left(t_{1}\right)$.

- Additional information for quality control purposes may be generated by a combination of multiple information sources (that provide data) using information (data) fusion, e.g. by combining non-destructive testing and simulation [42]. Berger et al. laid out that "concurrent", "complementary" and "cooperative" integration types may be considered, depending on the amount and types of sensors that are being applied in combination. Following these authors, the method of combining data from a sensor network depends on the spatial and temporal relationship between the sensors.

The authors of this chapter forecast that in addition to regulatory requirements the availability of appropriate non-destructive testing devices for monitoring will in the medium term at the latest boost the frequency of their application, for instance, in adhesive bonding technology and especially in view of quality variables. We recommend identifying, monitoring and collecting high-quality data relevant to product quality. In the subsequent chapters, and especially in Chaps. 3 and 4, we will draw on subject matter expertise to characterise and categorise monitoring techniques and devices.

As depicted in Fig. 1.3, our quality monitoring approach will follow a description of a material analytical process considering an impacting probe $\mathrm{P}_{\mathrm{i}}$, a detected probe $\mathrm{P}_{\mathrm{d}}$ and their interactions with the investigated sample material. The $\mathrm{P}_{\mathrm{i}}$-sample

Fig. 1.3 The material analytical process considering an impacting probe $\mathrm{P}_{\mathrm{i}}$ (solid line) and a detected probe $P_{d}$ (dashed line) as well as their respective interaction volumes with the investigated sample material comprising the sample surface

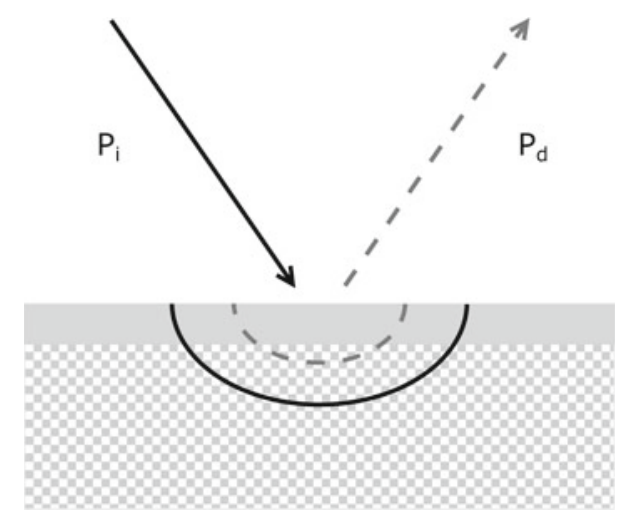


interaction volume may be larger than the information volume produced by the $\mathrm{P}_{\mathrm{d}}-$ sample interaction, but due to causality not vice versa. Finally, the focus will be on knowledge-based monitoring, which needs to answer the key question of this book: "How significantly does the state of the detected (set of) probe(s) $\mathrm{P}_{\mathrm{d}}$ depend on the state of the monitored operands?" Evidently, monitoring the state of the operators is equally essential.

We observe that advanced information in combination with cyber-physical systems is currently establishing the fourth generation of manufacturing [41]. Indeed, in the past two decades the assessment that "monitoring adds cost but no value and may save cost at a later stage" [32] may have even hampered the speed of innovation in quality monitoring techniques, since "it is very hard to get companies to invest in something of which the added value is vague" [43]. Based on interviews with representatives from the NDT sector, C. Wassink spotted that companies looking for NDT solutions appeared to do so at a rather low aggregation level (plant-by-plant basis), on a rather small time scale of weeks or a few months, and by predominantly addressing technical issues. Subsequently, he suggested that a new and alternative innovation mindset should be applied at the industry level and on a time scale of several years, advancing innovation by multiple iterations and improvements and by widening the focus from mere defect detection to safety and risk reduction considering the economic value and social acceptance. Such an approach was to be followed by "mixed teams of practitioners and scientists" that were formed "to launch and improve new innovative solutions" and to establish a shared vision and innovation model comprising the active role of NDT service providers.

Following this perception, we intend the present book and the presented work to contribute our subject matter expertise in analytics and in adhesive bonding technology to a vision implementing extended non-destructive testing, thereby embracing the far-reaching aspects underlying the concept of quality.

\subsubsection{Quality Assessment for Adhesive Bonding}

We dedicate this section to the advancement of selected aspects in quality assessment for adhesive bonding technology over the past quarter of a century. We decided to tackle this agenda by first inviting the reader to engage in some time travel to the past decade of the past millennium, to about 1990. The idea is that we intersperse numerous citations from the comprehensive report of the EUREKA research project EU716 "Quality Assurance in Adhesive Technology" authored by Espie et al. [32], which was already touched upon in Sect. 1.2.2 Quality Assurance and Monitoring, thereby highlighting the awareness and vision of 20 years ago. The reader will thus be given the opportunity to compare their experience and perception of the challenges and perspectives with ours, which will be detailed subsequently and can be summarised as follows: Basic requests for in-process QA in adhesive bonding technology have been persistent for the past three decades, and these have been expedited 
with increasing intensity from several aspects. It is expected that, with the achieved progress described in the following chapters of this book, they will advance quickly.

As outlined in the previous section, Espie et al. highlighted that quality management in adhesive bonding relies on two major concepts [32]:

(1) "The control of joint design and specification of materials and processes".

(2) “The process monitoring and/or inspection".

In line with this, over one decade later a typical QA program was said to be composed of three parts, including the aim of applying the QA concepts and reference to criteria for the acceptance of operands [44]:

(1) "Establishing limits on bonding process factors that will ensure acceptable joints and product".

(2) "Monitoring the production processes and quality of bond in joints and product".

(3) "Detecting unacceptable joints and product, determining the cause, and correcting the problem".

Nowadays, QA is assigned an even wider mission, embracing the service life of the product resulting from the bonding process. For example, sustainability is a central environmental, economic and social concern on the "adhesive bonding roadmap", which was recently published by Dechema (Society for Chemical Engineering and Biotechnology) and the Joint Committee on Adhesive Bonding (GAK), supported by the German Welding Society (DVS), the Research Association on Welding and Allied Processes, FOSTA (the Research Association for Steel Applications) and iVTH (International Association for Technical Issues related to Wood) [13]. This wider sense, based on the future-oriented public and technological perceptions, makes further "increasing the trust in adhesives" the essential caption on the frame of this roadmap. The three pillars for the roadmap are based on "managing production processes", "understanding ageing" and "computer-aided bonding (CAB)". Within the first pillar, aspired targets are "quality assurance using non-destructive testing methods" using standardisation, guidelines and training and with-on the horizon in the year 2025 - the "introduction of health and monitoring systems".

Thus, concerning quality assurance, we nowadays perceive that widening the focus to include economic value and social acceptance (as highlighted by Wassink [43]) is indeed a common sense in adhesive bonding technology. Moreover, it appears that after mastering static aspects, the upcoming decade will focus on assessing time-dependent changes within the operand materials during bonding and the application of adhesive joints. Following the up-to-date "adhesive bonding roadmap", managing a production process will embrace non-destructive testing, 100\% monitoring in production, networked systems and sensors, quality assurance and practical NDT [13].

What foundation has been laid in this regard over the past three decades? What contributions have promoted the progress beyond that which this book and its authors intend to highlight? In 1989, Light and Kwun described in a state-of-the-art report "the bonding process, the destructive methods used to measure bond strength, and the 
various NDE methods that have been evaluated for determining the quality of a bond. These NDE methods include sonics, ultrasonics, acoustic emission, nuclear magnetic resonance, X-ray and neutron radiography, optical holography, and thermography". They concluded that with respect to non-destructive evaluation (NDE), "each of these methods has shown some limited success in detecting debond conditions", and that "at the present time" partially a "potential capability to differentiate qualitatively the gradations between a good bond and a debond" is ascertainable, which may "provide a correlation to bond strength" [30]. Approximately ten years later, in the EUREKA EU716 project [32] it was claimed that in adhesive bonding processes "continuous monitoring and compliance with documented procedures are required to provide assurance of quality" because adhesive bonding is a special process. The "application of general quality management systems already in place in manufacturing industry" was one of the aims of this 3-year collaborative project between the Centre for Adhesives Technology at The Welding Institute (TWI), Cranfield University and the Department for Trade and Industry (DTI). The project "identified that highlighting design and production issue during very early stages of design" and "well before a component reaches the production stage ... enabled potential problem areas to be recognised and avoided". We will return to this latter (design) aspect and begin by reporting the details observed by researchers two decades ago.

In contact with eleven enterprises and institutions, exemplary manufacturing process checklists were completed in the EUREKA EU716 project by following the subsequent aspects/factors for describing and documenting the (two) adherends of adhesive joints:

- Description of the part,

- Manufacturer,

- Grade,

- Incoming specification,

- Supplier QA status, e.g. ISO 9001,

- Acceptance test(s),

- Sampling basis,

- Key attributes (critical factors), e.g. physical form, chemical composition, mechanical properties,

- Shape (critical factors), e.g. dimensions, tolerance,

- Surface condition (critical factors), e.g. as received, known contamination (like oil, grease, moisture, mould release agents, dust, dirt), existing coating,

- Required surface condition prior to bonding,

- Pre-treatment(s), listing process, materials, monitoring methods.

Among the required surface conditions prior to bonding, several of the following aspects were typically indicated by the contributing manufacturers:

- Not specified,

- No damage, e.g. intact peel-ply,

- Clean (we comment that from our viewpoint this could be "cleaned", i.e. with a cleaning process having been performed), grease-free, dirt-free, 
- Free of loose cement, gravel or dirt,

- Dry,

- No contamination from preceding processes (steps), e.g. free from abrasion debris,

- Untreated, or with pre-treatment (e.g. passivation, abrasion, as-processed, primer application) and optionally with calibration within $1 \mathrm{~h}$ of bonding,

- Surface tension $>56 \mathrm{mN} / \mathrm{m}$,

- Less than a maximum number of pin-holes per length (or area),

- Sterile.

Among the monitoring methods for pre-treatments, typically one aspect among the following optional methods was specified by the manufacturers:

- None,

- Operator control (for a solvent cleaning process),

- Visual examination, e.g. colour, side to be bonded, no evidence of contamination, clean and dull appearance of (abraded) surfaces, reflectivity, thickness control, optionally with specified illumination (e.g. strobe light),

- Surface temperature,

- Surface tension, e.g. ink,

- Non-oiled, handling kept to a minimum.

Further aspects recommended in the EUREKA EU 716 report to be considered for adherend materials checklists were appearance, surface energy, exposure, handling, storage, and despatch. We would like to highlight in this context that with a technological background the (informative) Annex A within "Adhesive bonding of railway vehicles and parts-Part 2: Qualification of manufacturer of adhesive bonded materials, English translation of DIN 6701-2:2015-12" [45] comprises an overview of relevant aspects ranging from assessing the main function of the bond, surface preparation, type of adhesive used, testing and degree of mechanisation.

The numerous and often rather qualitative selected aspects concerning the state of the adherend surface(s) before the application of the adhesive system reflect concerns that are common in adhesive bonding technology and which address the area that will contribute to the bond line of the resulting joint. The integrity of this region often is considered "a significant 'Achilles heel' in the outright acceptance of adhesive bonding in structural engineering" [46]. Following M. Michaloudaki, who refers to the situation prevailing in 2005, "the predominant strategy to quality assurance is based on destructive testing of the bonded joint with subsequent statistical evaluation". She points out that "this procedure is combined with high costs and does not allow $100 \%$ controlling of the components or a repair of defects occurring during manufacturing" and, moreover, that such "testing itself or process mistakes during manufacturing (e.g. false applicator nozzle positioning) inevitably lead to product waste". Essentially at the same time, M. Davis, a Principal Research Scientist at the Directorate General Technical Airworthiness of the Royal Australian Air Force attending a workshop of the Federal Aviation Administration in 2004 [47], reported some observations considered characteristic for applying adhesive bonding technology for the construction and repair of (military) aircraft structures. The author 
considered surface preparation to be the "most significant factor in long term bond durability", and claimed that failures are often "caused by ineffective processes not just contamination". He concluded that "a clean surface alone is not sufficient" and that "process specifications are useless unless properly validated". Among the "causes of service bond failures", the author listed "inappropriate quality assurance tests". With this respect, he reported that "NDT only tells of bond-line gaps", which may be a reason why "you never hear reports about good bonds". The situation that "some OEMs claim good bonds, blame failures on operators" might be overcome by a quality management that including as best practice "to manage quality through the process, not just to measure it after bonding". The author highlighted that with respect to repair bonding, "requirements are the same as construction" but "the processes are different", e.g. with regards to surface preparation or the heating and pressurisation because heater blankets and vacuum bags are often used instead of autoclaves during production. We would like to highlight the essential aspect of quantifying the process quality implied in these observations - an approach that has typically been based on mechanical characteristics in the past decade. Glancing at adhesive bonding as a substantial and complex technology, Niermann et al. [48-50], when reviewing and discussing quality assurance aspects, outlined the distinct phases and respective process steps, finally flowing into the manufacture of a well-designed adhesive joint, i.e. the planning, concept, design and final development as well as the production and the usage phases, which require cross-process quality assurance measures. A guiding mechanical principle was highlighted for proving usage safety: the load capacity throughout the service life must be greater than the expected loads. The authors stressed that in production, processing parameters are to be defined by manufacturers for cleaning and pre-treatment products, primers and adhesives, and-above all-that these must be observed. Any change in the parameters should occur (after being authorised) only after testing. Certified training courses in quality assurance measures for bonding technology were identified to help recognise and prevent errors from the beginning, and these were highlighted as an essential tool for quality assurance in adhesive bonding [50].

In this context of a complex technology based on numerous process steps, from a current viewpoint we would like to highlight again the relevance of the process chain characteristics when manufacturing adhesively bonded joints. Interfaces for handing over the operands from one process step to the next need to be as carefully addressed as the interphases between each adherend and the adhesive system. Global sourcing from multiple sources may result in process steps being performed at different locations and with a certain time delay, accompanied by storage, conditioning or transport operations [51]. For example, a cleaning step preceding the bonding steps is contained in most adhesive bonding processes. The process management in parts cleaning aims at ensuring "sufficient parts cleanliness as required for the respective follow-up process" with a minimal consumption of resources [52]. Consequently, within the bonding process chain an interface-comprehensive quality assurance concept is required, e.g. involving expertise from cleaning specialists and bonding specialists. Moreover, the exchange of quality-related information on the state of the operands is expected to be especially intensive at such interfaces, and 
in practice an all-over monitoring is aspired to, reliably linking the process steps to literally form a chain.

One accepted approach for assessing quality-related information about the state of the operands is to introduce a process-control specimen which (i) accompanies the production (or repair) parts throughout the phases of cleaning, assembly and cure $[45,53]$, and (ii) remains accessible in the cured state for destructive testing, thus documenting the effects of the performed bonding process. A second approach is highlighted in this book and is based on extended NDT, comprising (i) in-process monitoring of the actual operands by performing time-dependent control within the very regions of technological relevance and (ii) post-process characterisation of the resulting adhesive joints.

Generally speaking, we consider the objective in applying techniques to monitor materials in the frame of manufacturing processes the same as two decades ago: contributing to collecting and documenting facts [32] which support safeguarding the compliance of the state of the material with the requirements, which are typically set during the process qualification. This objective indispensably holds true for the material state, which corresponds to the product of the manufacturing process. Concerning quality assurance in adhesive bonding technology and visualised in a pyramid model in Fig. 1.4 (which is based on Fig. 1.1), considering additional elements of upstream quality assurance is highly recommended. Technical provisions for pre-process

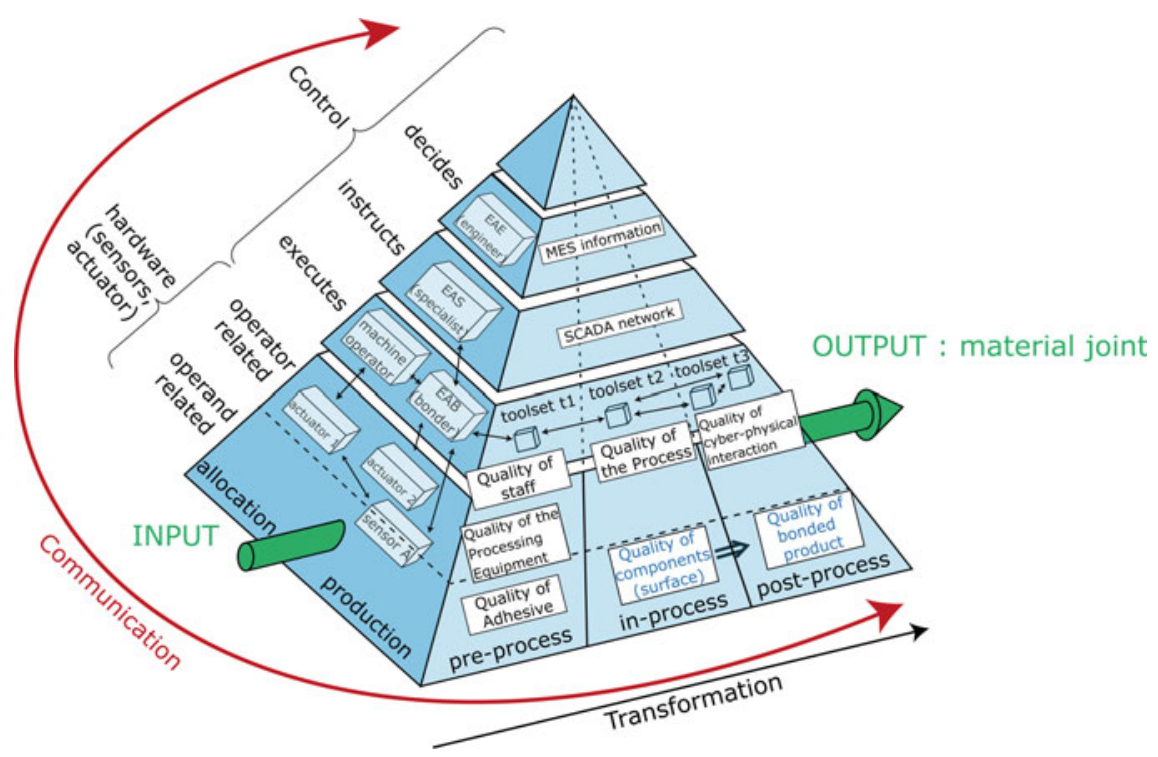

Fig. 1.4 Illustrative triangular pyramid showing actors-e.g. holding a European Adhesive Engineer (EAE) qualification - as well as material and process-related aspects contributing to quality assurance in adhesive bonding technology during manufacture or repair. The hidden and yet meaningful rearward face of the tetrahedron is related to ecological aspects. Quality topics in blue characters are the focus of the following chapters 
quality assurance, e.g. incoming inspection [54], and in-process quality assurance, e.g. after each production step [9], are requested. This is because the closer to the error source within the production chain the technologically relevant amendments for clearing material state deviations from the requirements are performed, the easier, more precise, faster, more sustainable and altogether cheaper they can be. In addition for the "continuous monitoring and control of process parameters", qualified operational staff and compliance with documented procedures, as claimed by Espie et al. [32], strongly contribute to the quality of adhesively bonded products. As highlighted in Fig. 1.4, great emphasis must be placed on employee qualifications, processes, reliable testing equipment and first-class communication [51]. We recommend considering interface-comprehensive communication among humans, between humans and machines (HMI or also human-computer interaction-HCI), and exchange within cyber-physical systems (CPS) in this context.

From the analytical point of view, the implications for the monitoring techniques and processes are manifold. A suitable monitoring should facilitate a comparison between the actual states and the target states of the process and the material, i.e. the states of the operators and the operands, and relevant deviations from the qualified target state should be significantly and reliably be indicated. With the target state typically being defined by a data interval, the monitoring process shall facilitate a differentiation between, on the one hand, states corresponding to the boundaries of that interval and, on the other hand, states corresponding to the centre of that interval.

In regard to monitoring in adhesive bonding technology, the analytical requirement for an in-process monitoring process is, therefore, much less complex than predicting the extent of property deviations for the ultimately manufactured adhesive joint or predicting properties which are not accessible without destructive testing, like the initial (or even the final) joint strength (respectively fracture toughness), which is often a fundamental design specification. In other words and in view of the formalism represented by Eq. (1.1), the monitoring is clearly not intended to contribute to assessing $S_{\mathrm{f}}^{\prime}=\mathbf{T}^{\prime}\left(\mathrm{t}_{\mathrm{f}}\right) \mathrm{S}_{\mathrm{i}}^{\prime}$ in the case that the initial feature vector $\mathrm{S}^{\prime}\left(\mathrm{t}_{0}\right)=\mathrm{S}_{\mathrm{i}}\left(\mathrm{t}_{0}\right)+$ $\Delta S_{i}$ deviates from the qualified feature vector $S_{i}$ or in the case that the process characteristics $\mathbf{T}^{\prime}\left(\mathrm{t}_{1}\right)=\mathbf{T}\left(\mathrm{t}_{1}\right)+\Delta \mathbf{T}$ deviate from the qualified ones $\left(\mathbf{T}\left(\mathrm{t}_{1}\right)\right)$ Rather, monitoring is intended to contribute to revealing whether $\Delta \mathrm{S}\left(\mathrm{t}_{0}\right), \Delta \mathrm{S}\left(\mathrm{t}_{1}\right)$ or $\Delta \mathbf{T}\left(\mathrm{t}_{1}\right)$ are acceptable based on the qualified corridors, i.e. the parameter ranges which conform with the qualification. Therefore, the analytical requirement for a monitoring process is "to look at trends and changes (or the lack of them) over time to reveal actions necessary to be taken with processes and the system, or to confirm that all is well" [32]. Concerning the surface properties of adherends before the application of the adhesive system in a bonding process, the lack of changes or differences as compared to the qualified process may reveal that the adherends are "ready to bond" based on the requirements of this particular process, the material combination and the application by customers. Clearly, among the required surface conditions listed above an attribute like "bondable" was not indicated, possibly due to the fact that it can hardly be considered a metric, numerical or steadily continuous material feature. In contrast, "ready to bond" is considered to refer to the feedback given to a technical operator or worker within the bonding process and is accounted for by the bonding 
supervisor in charge [11]. Such feedback is based on comparative monitoring and evidence of compliance with the quality/requirement-relevant data obtained for a qualified benchmark system. Finally, from the user's point of view the monitoring should be plausibly applicable in-line, in a non-destructive way, and executed at all positions relevant to the technical properties of the product.

Further aspects intended to spur the approach between monitoring system providers and users in adhesive bonding technology will be developed in the subsequent sections.

\subsubsection{Ten Heuristic Quality Assessment Principles for Adhesive Bonding Processes}

In this section, we present some qualitative aspects for discussion which we consider relevant for assessing quality assurance in adhesive bonding processes [55]. We call them heuristic principles and understand them here as a kind of set of pragmatic rules of thumb which will need to be refined by ongoing research; nevertheless, we have formulated and recorded them to support the reader in directing quality assessment in the direction of understanding and interpreting quality-related data rather than merely gathering them. Inherently, these principles may become a starting point for developing a guide for recommended practice. These heuristics are also intended to be principles in the sense of a starting point for iteratively improving the steps of the QA system. This improvement will contribute to further developing a superordinate quality management system that contains targeted actions in cases where the QA indicates quality-related issues. Based on experience (e.g. from the ENCOMB project [27], detailed in the subsequent section), discussions (e.g. within the ComBoNDT team [28] or with colleagues at Fraunhofer IFAM), ongoing literature studies (e.g. aspects from Nielsen's contributions concerning the usability design of user interfaces [56], or the methodology for discovery described by Kleining and Witt [57]), we propose a consideration of the following ten heuristic QA principles when targeting user-friendly quality assurance for the discovery of possible errors in adhesive bonding processes.

Heuristic Principle 1: "QA during an adhesive bonding process shall comprise the initial state of the operands, i.e. the adherends and the adhesive system, as well as their final state, i.e. the adhesive joint".

- An incoming component inspection is to be performed.

- At the start of the bonding process, i.e. at the initial time $t_{0}$, the initial state of the operands shall be characterised and documented. At best, this may include properties beyond the quality-relevant features.

- During the bonding process, the complexity of the operands' property vector may be reduced by following a feature vector, which considers surface and bulk 
features. The data resulting from monitoring these features are documented within the data vector.

- At the end of the bonding process, i.e. at the final time $t_{f}$, the final state of the operands shall be characterised and documented. At best, this may include properties beyond the quality-relevant features.

\section{Heuristic Principle 2: "QA shall comprise the time-dependent features describing the state of the operands and the acting operators".}

- The process-relevant features shall be identified and then monitored during the bonding process.

- Interactions between operands and operators are only accessible if the features of all operands and operators are measured, especially close to the bonding region.

- Time intervals between measurements shall be chosen reasonably; they ultimately govern the dimensions of the data matrix which comprises the data vectors obtained at distinct points in time.

- Referring to adhesive bonding technology, the period during which QA is performed may definitely go beyond the manufacture of the joints. This means that it may encompass the manufacture of the operands themselves in addition to the application of the joint (or non-destructive testing of the obtained joint when applying application-specific operational demands).

\section{Heuristic Principle 3: “QA shall be part of each step of an adhesive bonding process".}

- The bonding process is considered a process chain of subsequent process steps, with the chronological sequence being relevant ("non-commutative steps" that follow causality).

- The time resolution of an assessment embracing the initial and final states of the operands shall be improved by pursuing QA for each step within each phase of the bonding process.

- The monitoring shall comprise process parameters (characterising the operators) and quality-relevant features (characterising the operands), and the acquired data shall be evaluated and rated following the QA approach.

\section{Heuristic Principle 4: "The status of the QA monitoring system shall be made perceivable".}

- The monitoring system shall be regularly calibrated using reference calibration standards and reference materials, and the determined status of the instrumentation shall be displayed.

- The monitoring system and the subsequent data evaluation procedure shall indicate to the adhesive bonding supervisor and to the respective worker the level of quality of the performed measurement. Measurements of low quality shall be rerun. 
Heuristic Principle 5: "As a result of a QA inspection, the QA system shall give digital documentation/reports to the adhesive bonding supervisor and indications shall be passed to workers".

- The inspection system indicates information about the state of the bonding process; decisions are taken and imparted by (interacting) persons who are part of the adhesive bonding staff.

- An in-process and real-time availability of such information is often desirable during the manufacture and repair of adhesive joints.

Heuristic Principle 6: "The position inspected by the monitoring systems shall be promptly linked with the progressive position within the operand".

- User-friendly representations of spatially resolved monitoring data should be referenced to visual documentation (e.g. by scaled photographs) considering the magnifications.

- For user-friendly representations of several discrete spatially resolved qualityrelated data, the monitored regions of operands should be located considering their relative orientation.

- The time of the monitoring should be indicated and it should be referenced to the moment of the process start.

- Besides the spatial relationship between several monitoring devices and monitored regions, the temporal relationship between the acquired data also needs to be considered.

Heuristic Principle 7: "Consistency with the DIN 2304 standard and the qualified bonding process shall be assured".

- These are the benchmarks to be achieved during a manufacturing or repair process. Specifically, not only must non-bonding situations, such as a (local) lack of adherend pre-treatment or adhesive application as well as kissing bonds, be avoided, but also good bonds must be safeguarded and documented.

- Consider all process-relevant and application-relevant factors (in a controlled system), involving the adhesive bonding supervisor in the QA process.

Heuristic Principle 8: "QA inspection shall help to optimize the bonding and the QA processes".

- The monitoring of quality data and process data for the operands and operators as well as their evaluation and rating shall be documented.

- Workers shall be continuously educated and trained to contribute process-relevant perceptions. Subjective observations and information given by workers shall be stimulated and taken seriously and shall be documented and evaluated, aiming to make them objective.

Heuristic Principle 9: "QA data shall be collected under the paradigm of the maximum structural variation of perspectives" 
- During the qualification of the manufacturing or QA processes, the expected variability of well-defined initial sample states shall be considered by scheduling intervals of acceptable feature values.

- When performing monitoring, different (modes of) ENDT techniques shall be considered. In detail, several mono-modal ENDT techniques may be applied or multi-modal techniques shall be used.

- Time-dependent or stimulus-responsive interactions between ENDT probes and the materials to be investigated shall be considered, both when documenting the parameters of the ENDT data acquisition and when elaborating ENDT procedures.

\section{Heuristic Principle 10: "Analysis of QA data shall embrace the discovery and quantification of similarities".}

- A first question to be quantitatively answered by the data analysis shall be "How big is the similarity to the qualified operand state?"

- When an error is detected, a second question to be quantitatively answered shall be: "Is the error pattern similar to known operand states which were deemed necessary to reject during qualification?"

- Check the observed changes in process parameters and quality parameters for common time-dependent trends, patterns or correlations.

- Basically, this aspect assesses part of the Industry 4.0 cyber-physical connection and smart manufacturing because it aims to gain information by understanding patterns and rooting causes to their situation and use cases [24, 37].

We anticipate that the thus assessed quality-related data sets will be amply accessed for documentation, reporting and evaluation purposes. In particular, capturing the features describing the actions of relevant operators contributes to preserving often proprietary manufacturing domain knowledge, which presently may only reside in the heads of engineering staff [21]. Evaluating the monitored operandrelated features in the framework of manufacturing control will form the basis of rule-driven decisions [21], for example, determining if a certain time-dependent operand state is to be classified "in order" (or "not in order"), if actions are to be taken, or which actions are expedient. On the one hand, we expect that such rules and the recipes to be followed will be based on human reasoning in the decades to come, but the availability of binary data will help to enhance and refine the criteria upon which these rules work. On the other hand, documenting such rules themselves, the human reasoning and strategies behind them as well as the decisions taken and the formalised recipe to be followed is a task for the steady optimisation of the interacting QA and quality management systems. We assert that this task will be supported by ontologies. Therefore, we recommend applying a clear-cut taxonomy for the elements of a production or repair process, and the things or concepts which are subset to "operator" or "operand" will be specified with greater clarity, more concretely, and customised for each manufacturing site.

Assessing sets of binary data which represent quality-relevant operand features will be detailed in the following chapter. We will highlight, on the one hand, CFRP adherends and adhesive joints thereof as exemplary and descriptive materials and, on 
the other hand, NDT tools to monitor the quality-relevant features of CFRP adherends and/or adhesive joints thereof in the frame of quality assessment. Afterwards, we will introduce a concept for quality assessment in adhesive bonding which is based on these environments, our experience and human reasoning.

\subsubsection{Extended Non-destructive Testing for Bonding CFRP}

In this section, we do not comprehensively survey all ENDT approaches, but instead focus on the characterisation of composites based on fibre-reinforced polymers (FRP), especially carbon FRP (CFRP), distinguished by layers made from electrically conductive long fibres. We may highlight that the performance of adhesively bonded joints manufactured from such composite materials depends on the intensity of the operational loads to which the adhesive bond is exposed during in-service operation (e.g. of an aircraft), on the density and size of defects such as debonds, pores and delamination, and on the physico-chemical properties of the adhesive bond. While the operational, environmental and mechanical loads are considered in the structural design, the question remains as to how issues regarding the quality assessment of the joints contemplated here were considered and tackled at the end of the first decade of the third millennium.

In a nutshell, we may state that the defects in the joint area could (and still can) be detected by means of conventional NDT. However, there were no methods available to test the physico-chemical properties of adhesive bonds. In more detail, we present the complex line-up starting with the requirements for the said joints and the main parameters affecting the product quality, which comprise the surface treatment, joint configuration, geometric and material parameters, and failure mode $[34,58]$. In their recent review, Budhe et al. stress that the durability of adhesive joints is governed by environmental factors such as temperature and moisture (including prebond moisture). Especially in the manufacture of automotive parts made from CFRP, variations in material quality (e.g. the thickness of the fibre-covering polymer matrix) or a variety of different contaminations, to some extent with considerably varying surface concentrations $[16,59,60]$, call for the implementation of in-process surface quality monitoring, e.g. using scattered light technology. Concerning the repair of FRP structures, as for any substrate "skilled repair technicians, good surface preparation, well-designed repair procedures and the use of first-rate materials" are required [61]. The National Composites Network Best Practice Guide further highlights "stringent quality control encompassing reliable damage detection, surface cleanliness and texturing examination, drying to known limits, undertaking work within permitted temperature and humidity envelopes, and controlling resin cure to manufacturers' recommendations", "followed by NDT inspection of the finished repair or destructive testing of sample coupons or bars". During a typical repair procedure, thorough cleaning and degreasing may be succeeded by a water-break test and thorough drying [61]. After finishing the repair, inspection and certification of the resulting outcome are recommended [61]. 
Considering the quality assessment in more detail, the available NDT tools which can be applied during the production of FRP composites comprise facilities for monitoring the flow front, curing degree, void content, and possible delaminations (between matrix and fibres), for which established and various techniques are available, e.g. based on the electromagnetic, optical, mechanical or thermo-dynamical properties [17]. We may summarise that quality assurance processes for adhesively bonded CFRP primary structures that are not load-critical existed and were applied. Adhesively bonded structures were (and are) inspected by means of such conventional NDT in order to detect defects like pores, debonds or delaminations in the joint area. The materials (e.g. adhesives, prepreg materials) and process parameters (e.g. surface treatment, curing) were also controlled and monitored. In addition, specimens that had run through the complete manufacturing cycle were tested by both non-destructive and destructive methods to identify systematic process failures. However, in order to ensure the performance of adhesively joined load-critical CFRP structures, technologies suitable for the detection of the adhesion properties of bonded components were required [27]. Driven by central challenges within the aeronautics industry and with the above-mentioned requirements set, the ensuing development and adaptation of ENDT methods for the pre- and post-bond inspection of CFRP aircraft structural components is ongoing [62], and it is being expedited as a basis for establishing a reliable quality assurance concept for adhesive bonding. Briefly, as introduced in the ENCOMB project [27], the principle of such ENDT methods is based on the detection of selected physico-chemical properties which are important for the performance of an adhesive bond. Within the ENCOMB consortium, leading experts in aeronautics research and development from ten European countries cooperated to provide advanced non-destructive testing methods for reliable quality assurance of adhesive bonds in CFRP structural components, respecting the fundamental aspects most relevant from a manufacturer's and ENDT user's point of view. The constellation is schematically depicted in Fig. 1.5.

Two essential questions to be answered during the ENCOMB project were the following:

- From the point of view of the manufacturing process: "Which changes in which physico-chemical properties of the adherend surfaces and adhesives (i.e. the discrete operands) result in which changes to the properties of the adhesive bonds (between the joined operands), such as mechanical strength?"

- From the point of view of a feasible monitoring process: "Does a deviation in the state of the monitored operands influence the state and distribution of the detected (set of) probe(s) $\mathrm{P}_{\mathrm{d}}$ ?"

Concerning the physico-chemical properties of adherend surfaces, the degree of contamination or the type and level of surface pre-treatment, for example, needs to be considered. The physico-chemical properties of adhesives depend on a range of conditions, from the curing parameters and age of the adhesive, to the application parameters and ambient conditions. The adhesion, the morphology of the interphase and the cohesion of the cured adhesive are a direct product of these properties and 

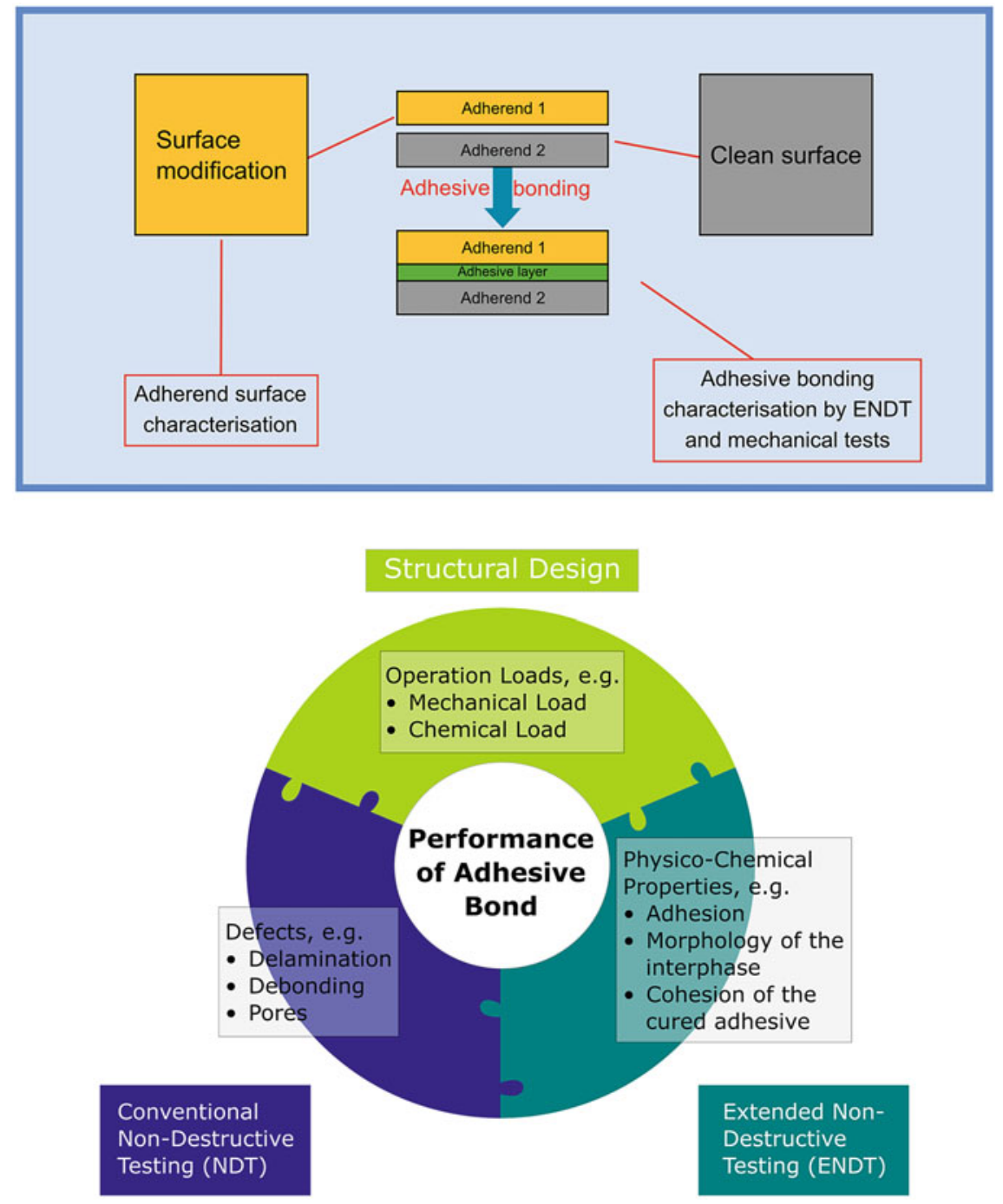

Fig. 1.5 The target and procedure of the ENCOMB project [27]. The focus of this project was to identify, develop and then adapt methods that are suitable for the assessment of adhesive bond quality, comprising investigations of CFRP adherend surfaces and adhesives. Not only the detection capabilities but also the sensitivity of measuring techniques were tested, evaluated and improved in order to achieve analytical results that could be quantified 
are fundamental to the strength and durability of the adhesive joint. If the physicochemical properties of adhesive bonds are not sufficient, then adhesion failure, weak bonds or bonds that weaken in-service can occur. Based on this rationale, ENCOMB identified and provided promising and developable non-destructive testing (NDT) methods for the pre- and post-bond inspection of CFRP aircraft structural components. State-of-the-art NDT techniques were screened, with the most suitable being adapted to important application scenarios with regard to aircraft manufacturing and in-service repair; finally, the performance was validated.

From the point of view of joint manufacture, the physico-chemical properties of CFRP adherend surfaces and the quality of the adhesive bonds were affected by intentionally applying different contamination levels down to the threshold levels of an insignificant impact on bond strength. From the point of view of identifying capable ENDT technologies, a screening was performed from among 31 technologies. Technologies facilitating a differentiation between treated specimens and a clean reference specimen were then adapted and validated in five different application scenarios that had been identified as being of primary importance for aircraft manufacturers. For each of the application scenarios, several techniques were developed that were able to detect different contamination levels and that had passed the validation step. Furthermore, several techniques with good potential were also developed further to comply with the requirements.

With these advancements in mind, we may state that research and development in extended non-destructive testing have been ongoing for over a decade, and the advances are increasingly providing tools and procedures for approaching the technical aspects of quality assessment in adhesive bonding technology. The trends we perceive in terms of progress in monitoring and the growing impact facilitated by ENDT are highlighted in Fig. 1.6.

Details of several promising ENDT techniques as well as their present performance and future potential in adhesive bonding technology are presented in the subsequent chapters. The contributions in this book highlight the development status which, as compared to ten years ago, clearly exceeds the prototyping stage, as will be substantiated by the assessment of the respectively accomplished technology readiness level (TRL). That being said, we are aware that the development of ENDT techniques is at present very dynamic, and we are confident that further progress will be achieved over the decade to come, motivated by the increasing interactions and exchange of views between specialists in the fields of monitoring, quality assurance and the manufacture and application of adhesive joints, accompanied by increasing standardisation.

To exemplify the technological perspectives of ENDT for the decade to come, we will focus on two of the surface-sensitive ENDT techniques, namely the aerosol wetting test (AWT) and optically stimulated electron emission (OSEE), and deduce advancements that may be achieved based on evaluating the dynamics of the respective measuring processes. Presently, key information is gained from the signals measured after a certain fixed period of time, starting with the deposition of primary liquid droplets or with the ultraviolet light illumination of the solid adherend surface, respectively. This observation implies on the one hand that these time periods need 


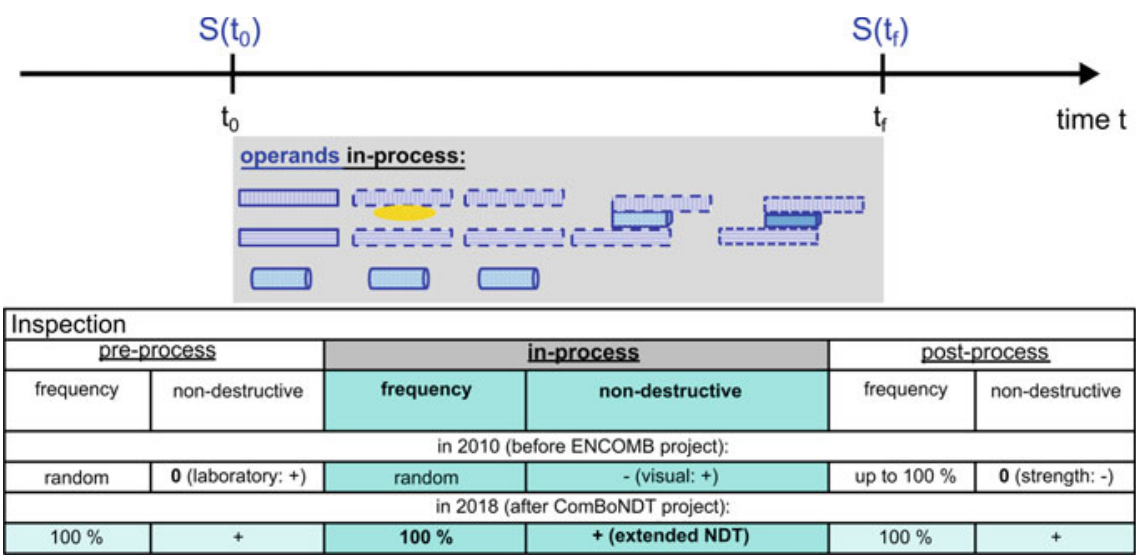

Fig. 1.6 The fields of application for the inspection of operand-related and process-relevant material features, considering the schedule of an adhesive bonding process and thus, comprising incoming inspection, manufacturing (or repair) inspection, and final inspection. The domain for ENDT inspection is shaded blue, and the basic contributions achieved in the ENCOMB [27] and ComBoNDT [28] projects are highlighted. We evaluated the availability and distribution of the respective inspection tools and procedures qualitatively and indicate our rating by " + " (widespread), " 0 " (temporary), or “-” (rather rare)

to be carefully documented among the ENDT measuring conditions in the respective metadata set. We expect that this will call attention towards standardising formats for documenting these metadata, e.g. for achieving interoperability, for instance, following the approach developed by Allotrope Foundation [36]. On the other hand, any observed time-dependent effects on the data may provide additional information about the adherend surface state and may even be purposefully triggered or stimulated. For the examples of AWT or OSEE based surface inspection, additionally accessible adherend surface properties might be the rate of liquid (droplet) evaporation or the electrical charging upon electron emission. Prospectively, the optically stimulated electron emission of an adherend surface may be purposefully modified by the stimulus, which is temporarily effective during an AWT measurement, i.e. by the deposition of aerosol droplets. A stimulus-responsive ENDT (SR-ENDT) approach may be realised in this way [63].

As anticipated in Fig. 1.6 and as a first-hand example of advancing ENDT towards a new and hopefully brilliant horizon, the following scope of this book is attributed to the progress and outcomes of the three-year Horizon 2020 European research project ComBoNDT [28]. 


\subsubsection{Concepts for ENDT and Quality Assessment in Adhesive Bonding}

In this section, as a consequence of the above-mentioned considerations for ENDT and quality assessment in adhesive bonding, we exemplarily describe for the reader a feasible concept which complies with the ten heuristics and the systematics upon which the approaches described above are based, while also providing a comprehensive and customisable toolbox and schedule for implementing monitoring-based decisions in a quality assurance system.

Following this concept, sets of several empirically obtained correlations will have to be compiled between, on the one hand, destructively tested quantitative and designrelevant joint features and, on the other hand, operand-based quality data measured during the manufacture or repair of adhesive joints using ENDT. Each correlation is obtained by systematically introducing disturbances of one operator-related process feature (as performed within the ENCOMB project [27]), or even by introducing disturbances of several process features together in a set (as performed within the ComBoNDT project [28]). For example, a disturbance of one operator-related process feature might be due to contacting the adherend surface, such as when the finger of a worker touches freshly cleaned CFRP material. As a consequence, a deviation of the material state from the requirements may result because during the contact time some material may have been transferred from the finger to the CFRP surface. Strictly speaking, the process characterised by accidentally touching the surface may be referred to as a contamination (or a contamination operation), while the material transferred as an effect of this process is a contaminant (or contamination agent) affecting the CFRP surface quality. While bearing in mind the differences in meaning behind the words, the contemplated phenomenon might simply be referred to as a contamination. However, the exemplified approach based on semantics highlights that consciously recognising the cause-and-effect chain during a process chain is a basic element of the quality assurance process, which may be built on monitoring causes or effects (or even both) in the course of the quality assessment.

The working hypothesis behind the concept that we introduce to the reader is the following. If all feasible (or pragmatically all imaginable) disturbances of process features are identified, implemented and their effects tested, then such a set of all feasible (or imaginable) empirically obtained correlations (based on the respectively measured ENDT data sets and the data sets resulting from testing quantitative and design-relevant joint features) will reveal

- Whether applying selected ENDT investigations will to a full extent provide quality data that allow an identification (during the manufacture or repair process) of all feasible (or imaginable) joints that will not fulfil the design-relevant joint requirements as given by the qualification procedure;

- Whether one or several ENDT methods (or the measurement modes of multimodal ENDT tools) will be necessary to obtain a set of quality-related data which covers and provides significant quality-relevant information for all feasible (or imaginable) disturbances of process features; 
- Which measures of quality assurance are required in order to clear the detected distinctive quality-related operand features of the particular joint;

- What the consequences are when potentially clearing quality-assurance actions are taken in response to detecting a "not in order" state of the operands (already during manufacture or repair);

- Which operator-based measures of quality assurance are required in order to avoid a recurrence of the observed variation in quality.

The concept thus relies on evaluating experimentally acquired data sets, and we intend to devise a way towards an elaborate data acquisition process on the basis of the following steps:

- The identification and quantification of feasible (or pragmatically all imaginable) disturbances of process features;

- The separate or combined implementation of the identified and quantified disturbances in the fabrication of specimens, e.g. adhesive joints; testing and quantifying the effects of an implemented quantified disturbance applying;

- An in-process quality assessment of operand-related features (e.g. using ENDT approaches and methods), specifying both the limit and the probability of detection (POD);

- A post-process assessment of quantitative and design-relevant operand features (e.g. performing destructive testing to determine the strength or fracture toughness, including an inspection of the fracture pattern);

- Plotting the data set obtained by post-process assessment against the data set resulting from in-process assessment, highlighting the significance of the considered operand feature for the quality of the product, with the obtained relationship being specific for each implemented disturbance.

We are aware that applying (at least) the integral parts of such a concept is presently becoming increasingly widespread and is entering the phase of research, development and technology $[15,16,63,64]$. In this book, we highlight the usefulness of our application-oriented approach in a descriptive and concrete way.

The subsequently discussed set of sketches shown in Fig. 1.7 displays how an application-relevant "not in order" statement which is based on destructively testing quantitative and design-relevant operand features (denoted as Y), may be translated to a threshold criterion related to an ENDT data set that comprises information on quality-relevant operand features (denoted as y). In Fig. 1.7 we imply that instead of the directly measured quality-relevant operand feature itself, its deviation from the value obtained during the process qualification is considered. In an example of use based on non-destructive quality assessment in adhesive bonding manufacturing, we note on the one hand that following a common qualification procedure the designrelevant operands feature $\mathrm{Y}$ may be joint strength, as obtained in a defined test bench for as-manufactured or aged adhesive joints. On the other hand, following an expedient ENDT monitoring procedure, a quality-relevant operand feature y may be the surface wetting behaviour of one adherend, as obtained with a process-integrated 


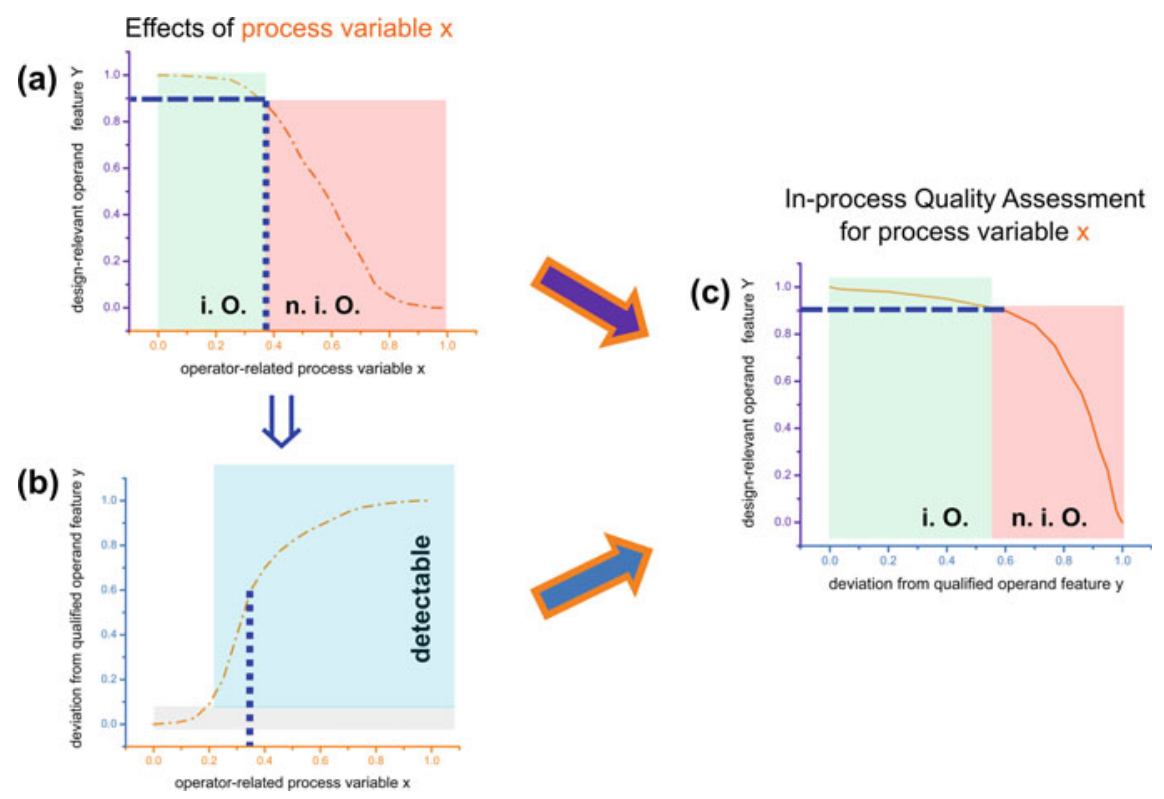

Fig. 1.7 Schematic introduction to the concept of ENDT and quality assessment in manufacturing processes, e.g. in adhesive bonding. For exemplification, the two functions $\mathrm{y}(\mathrm{x})$, and $\mathrm{Y}(\mathrm{x})$ were selected as one-to-one functions in a way that for each value of operator-related process variables, i.e. $\mathrm{x}$, one value results in each one of the operand features $\mathrm{y}$ or $\mathrm{Y}$. Y represents a design-relevant operand feature, and y represents a quality-relevant operand feature. On the left column of the plots, the functions $\mathrm{Y}(\mathrm{x})$ and $\mathrm{y}(\mathrm{x})$ are displayed, and on the right column the correlation $\mathrm{Y}(\mathrm{y}) \mathrm{I}_{\mathrm{x}}$ is shown, tied with the boundary condition that the regarded process variable is $\mathrm{x}$. More details can be found in the text

setup prior to the bonding step. Basically, the correlation $\mathrm{Y}(\mathrm{y}) \mathrm{I}_{\mathrm{x}}$ links two observable responses of testing procedures, with a $\mathrm{Y}$ and $\mathrm{y}$ pair being obtained for the same disturbance $\mathrm{x}$ of the qualified bonding process.

We would like to accentuate that this set of sketches in Fig. 1.7 illustrates the following:

- Figure 1.7a shows that the accuracy of the experimental approach may iteratively be optimised aiming at finally introducing any disturbance in a way that its grading (e.g. represented by levels of intentionally applied contamination) is particularly fine around the crucial value of the regarded process variable (denoted here as $\mathrm{x}$ ), which corresponds to the "in order"/"not in order" transition point of the design-relevant operand feature Y; we would like to highlight here that such an optimisation was one of the advancements achieved in the ComBoNDT project as compared to the ENCOMB project;

- Figure $1.7 \mathrm{~b}$ shows that variations around the crucial value of the regarded process feature $\mathrm{x}$ should manifest in significant signal alterations upon an in-process assessment of quality-relevant data y (e.g. concerning the signal obtained when 
applying ENDT; a minimum requirement is thus that the respective feature is detectable by the ENDT investigation);

- Figure $1.7 \mathrm{c}$ shows that the result of an in-process quality assessment might anticipate the "in order"/"not in order" categorisation which will be revealed by the post-process inspection $\mathrm{Y}(\mathrm{y}) \mathrm{I}_{\mathrm{x}}$ of the manufactured specimen only if precisely that investigated process feature $\mathrm{x}$ is the only uncontrolled feature of the inspected process;

We would like to accentuate that the set of sketches in Fig. 1.8 aims at a more elaborate contemplation and illustrates the following:

- Figure 1.8a corresponds to Fig. $1.7 \mathrm{c}$ and is related to effects resulting from the impact of process variable $\mathrm{x}$.

- Figure 1.8c, d, which are similar to Fig. 1.7a, b but address a different process variable (namely $X \neq x$ ), show that the progression of the characteristic line $y(X)$ is sketched differently from $y(x)$, which is done to indicate that it is usually specific, e.g. for the respective intentionally applied contaminations;

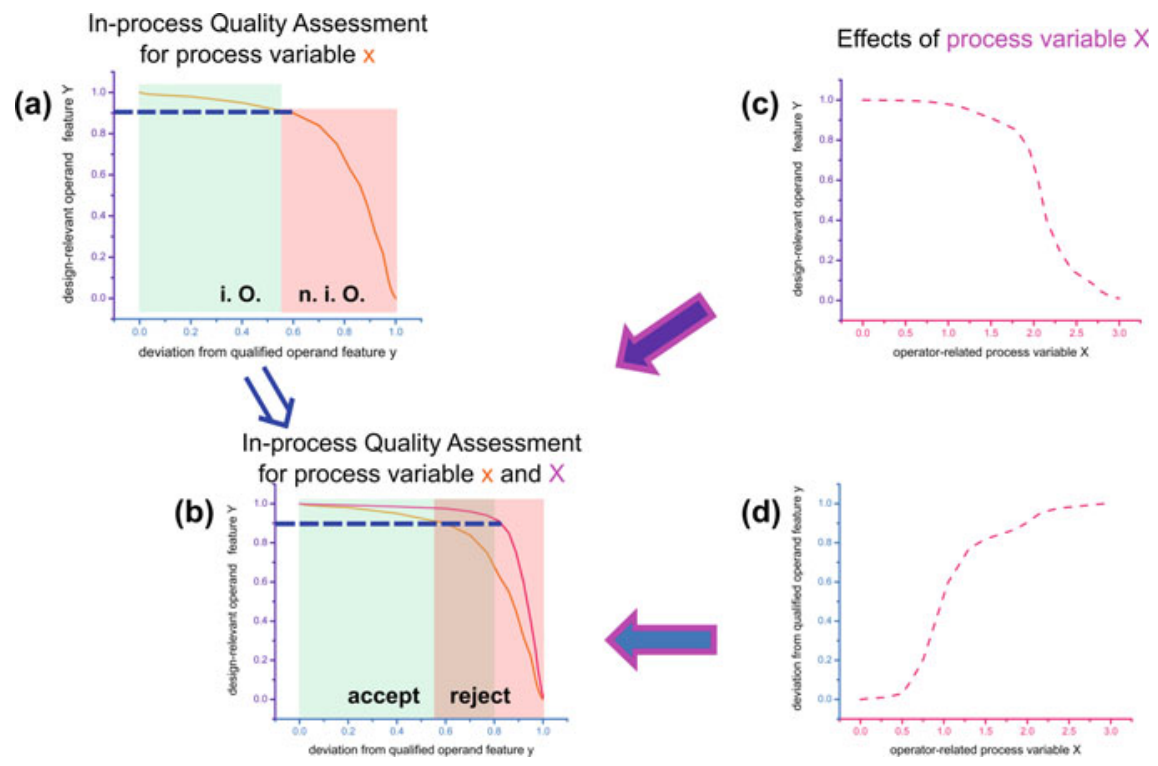

Fig. 1.8 The elaborated concept of ENDT and quality assessment in manufacturing processes, e.g. adhesive bonding, which is central to this book. For exemplification, the four functions $y(x), Y(x)$ as well as $\mathrm{y}(\mathrm{X})$ and $\mathrm{Y}(\mathrm{X})$ were finally selected as one-to-one functions in a way that for each value of operator-related process variables, i.e. either $\mathrm{x}$ or $\mathrm{X}$, one value results in each one of the operand features y or Y. Y represents a design-relevant operand feature, and y represents a quality-relevant operand feature. In the left column of the plots, the functions $\mathrm{Y}(\mathrm{y}) \mathrm{I}_{\mathrm{x}}$ and finally both the functions $\left.\mathrm{Y}(\mathrm{y})\right|_{\mathrm{x}}$ and $\left.\mathrm{Y}(\mathrm{y})\right|_{\mathrm{X}}$ are displayed (in plots a and $\mathrm{b}$, respectively). More details can be found in the text 
- Figure 1.8b, which is the aggregation of the sketches in Fig. 1.8a, c, d, shows that to avoid false positives, the decision to set a threshold value in a binary in-process categorisation is governed by the most sensitively detected process disturbance whenever more than one process variable may not be controlled in-process.

We prominently applied the presented concept in the ComBoNDT project [28], which is introduced in the next section.

\subsection{Recent Joint Research for Advancing QA in Adhesive Bonding}

In the following subsections of the present chapter, we will introduce the reader to the framework of the joint research project "Quality assurance concepts for adhesive bonding of aircraft composite structures by advanced NDT" (ComBoNDT) [28] and address its characteristics as well as the beating heart of this project, namely our consortium. This project received funding from the European Union's Horizon 2020 research and innovation programme under grant agreement No. 636494 and our consortium was active from 01-05-2015 to 30-04-2018 to achieve substantial progress beyond the starting position described in the previous chapter. The present book is based on the advances for quality assessment in adhesive bonding technology which were achieved over the course of the EU Framework Programme for Research and Innovation aspiring for smart, green and integrated transport. Briefly, the input and the output provided by the ComBoNDT project is essential but not confining for this book, and all authors of this book contributed to this project.

Subsequently, we will detail the overall concept, the goals pursued in this book, the step-by-step planning towards the achievement of the goals, the strategies followed as well as the intended impact according to the project workflow.

\subsubsection{Objectives and Rationale}

The context in which we were working had previously been defined by the key performance indicators (KPI) of the European aeronautics industry as defined by Flight Path 2050 "Maintaining and extending industrial leadership" [65]. Among these KPI, "process time reduction $80 \%$, cost reduction $70 \%$, and competitiveness of products produced in Europe compared with those produced in low labor cost countries" were the key factors inspiring the activities performed early in the second decade of the third millennium. To this end, we aimed at the development of ENDT tools for CFRP, adherend surfaces and bonded CFRP joints that could potentially cope with the technological problem in two ways: 
- Safety improvement and cost reduction for building this kind of structure due to more reliable and longer lasting adhesively bonded joints

- Augmentation of the competitiveness of the European aeronautics industry by adopting such lightweight structures and joints, which may lead to a further cost reduction and greener air transport

More precisely, even though there is a strong need to exploit the potentials of lightweight CFRP structures in the aeronautic industry alongside the application of adhesively bonded joints, their adequacy for primary aircraft structures remains low. Despite the advances made in this sector as well as previous attempts, the shortcomings observed were caused mainly by the absence of adequate quality assurance processes. The corresponding requirements concerning the quality assurance of the manufacturing process of load-critical CFRP structures are particularly high, as potential failures could directly affect the overall safety of an aircraft.

Considering the above-mentioned aspects, the implementation of reliable adhesive bonding processes through advanced quality assurance would lead to the increased development of highly integrated structures with an optimum combination of advanced composite materials, which would, in turn, minimise the use of the rivet-based assembly. Consequently, metallic assembly concepts would potentially be surpassed through a redesigning of the structures. The benefits of such a procedure can be crucial, especially in the field of weight saving, which may be expected to amount up to $15 \%$ in the case of the fuselage airframe. This could have further positive effects on the size and weight of other aircraft parts, such as the engines or the landing gear, causing in parallel a reduction in both the fuel consumption per passenger-kilometre and the operating aircraft costs. Furthermore, a significant reduction in greenhouse gas emissions $\left(\mathrm{CO}_{2}\right)$ would contribute to the mitigation of climate change and further improve the environmental performance of the transportation sector.

The already established quality assurance processes for adhesively bonded CFRP non-critical load structures are based on measurements using methods suitable for the detection of potential defects (pores, debonds, delaminations) in the joint area. However, using such conventional NDT methods does not facilitate a detection of any further defects of interest, such as kissing bonds, nor does it assess the weakening of a geometrically intact bondline. Thus, the development of quality assurance processes which, on the one hand, provide a correlation to the physico-chemical properties of the probed adherends and adhesives and, on the other hand, could make the adhesion properties of bonded components accessible had to be spurred. This goal also met the EASA (European Aviation Safety Agency) certification requirements for structural bonding [66]. Our research and development (R\&D) in ENDT techniques aimed at establishing reproducible and reliable non-destructive inspection tools in order to ensure the manufacture of joint structures that reliably feature the required strength.

In a nutshell, our overall objective was to develop a quality assurance concept for the adhesive bonding of load-critical CFRP primary aircraft structures, which could be applicable within the whole life cycle of the aircraft to overcome the current limitations regarding the certification of composites. Therefore, we established a detailed 
approach regarding in-line ENDT for CFRP materials at an increased technological readiness level (TRL), both in-process and post-process.

Applying ENDT technologies, we aimed to overcome the limitations of conventional NDT methods and allow the reliable assessment of the surface state of CFRP adherends as well as the quality of the final adhesive joint. We focused on the implementation of previously developed ENDT techniques, their assessment and, potentially, the increment of their TRL. The integration of these techniques into future adhesive bonding process chains, quality assurance concepts and material testing for maintenance processes could pave the way for the safe and reliable integration of lightweight structures into aircraft design. Applying the bonding of complex lightweight structures and the replacement of the traditional riveting method may overcome the use of CFRP as a "black metal".

Among the most important topics to which the book aims to contribute is the establishment and strengthening of the production and material testing processes at all stages of an aircraft's lifecycle using the previously mentioned quality assurance concepts. A fast and precise detection of surface contaminations and defects like kissing bonds in bondlines could help save time (up to $70 \%$ time savings using ENDT) during production, maintenance, overhaul, repair and retrofit. This way, aircraft parts could be checked for contaminants without disassembly or time-consuming steps. Also, parts of the aircraft could be replaced or fixed when necessary, resulting in up to $50 \%$ higher cost efficiency for ground operations. All of the above will significantly contribute to the competitiveness of the European aircraft sector.

The advancement of highly promising ENDT technologies was necessarily tested and demonstrated exemplarily in the frame of two fields of application, namely aircraft manufacture and in-service bonded repair. These fields of application determine the requirements in terms of the detection capabilities (e.g. of unknown contamination), applicability and robustness (i.e. TRL) that need to be met by the ENDT technologies. The maturity of the techniques will also involve approaches concerning automation and industrialisation, which means that aspects like the mobility of the measurement setup, objective and unambiguous data evaluation and interpretation were also addressed. In more detail, among the main objectives for our research and development was the incrementation of the current maturity level (TRL 3-4) to a TRL of 5-6. The aim of an increased TRL was addressed both as a measurable project result and a ground-breaking step towards the implementation of the developed ENDT techniques in real application scenarios.

The improvement of material testing during manufacturing as well as ground operations (overhaul, maintenance) will allow the automation of processes that are currently performed manually. The resulting time savings (in combination with more reliable results) should also be utilised to obtain measurable results by comparing the state-of-the-art process with the newly developed techniques. An important step was therefore the determination and improvement of the performance of ENDT in terms of the speed of inspection and data evaluation (aim: $10 \mathrm{~min} / \mathrm{m}^{2}$ of the inspection area at three to five times faster than the current state of the art).

In summary, a successful $R \& D$ process would enable 
- The reliable and reproducible detection of unknown and potentially multiple contaminations on adherend surfaces;

- The reliable and reproducible detection of poor bond quality in bonded adhesive joints;

- A robustness of methods and a suitability for field measurements in aircraft manufacturing and repair environments in terms of detection limits and measuring speed;

- ENDT technique(s) which are validated in the relevant environments (TRL 5-6).

\subsubsection{Concept and Approaches}

Regarding the overall concept, the aircraft manufacturers within our project consortium provided the other partners with their demands and targets, aiming at the successful exploitation of the research activities. The sketch displayed in Fig. 1.9 summarises our overall conception of this book and its chapters:

We greatly benefited from the outcome of the EU FP7 project "Extended nondestructive testing of composite bonds-ENCOMB" [27], the results of which were detailed in the previous chapter. Launched back in 2010, ENCOMB involved a screening of potentially suitable techniques for the characterisation of CFRP adherend surfaces and adhesive bonds, whereby over 20 different non-destructive technologies were tested. Several contaminations or defects (e.g. a silicone-based release agent, hydraulic fluid, moisture, thermal degradation or poorly cured adhesive) were introduced to adhesively bonded CFRP joints in order to adapt the measuring techniques in such a way that the different contaminants and the resulting effects on the bond quality could be detected down to relevant threshold values

State of art

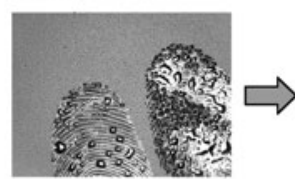

ENDT techniques can detect:

- Single surface

contaminations (prebond) on simple sample geometries

- Weak bonds due to single contaminations/poorly cured adhesive (post-bond) on simple geometries
Step 1

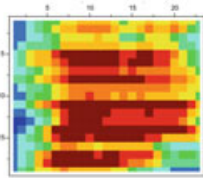

Maturation of ENDT techniques to detect:

$$
\begin{aligned}
& \text { - Different multliple surface } \\
& \text { contaminations down to a } \\
& \text { certain threshold value } \\
& \text { (pre-bond) on test } \\
& \text { coupons } \\
& \text { - Weak bonds due to } \\
& \text { multiple contaminations/ } \\
& \text { poorly cured adhesive } \\
& \text { (post-bond) on test } \\
& \text { coupons }
\end{aligned}
$$

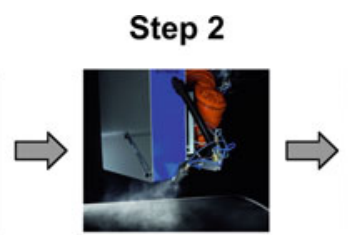

Adaptation and improvement of ENDT in terms of:

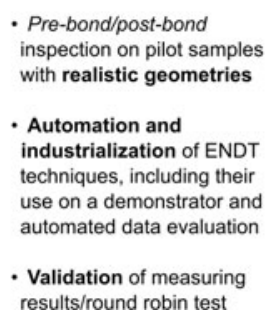

Innovations

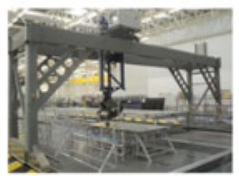

Validated ENDT techniques

for:

- Surface quality assurance (pre-bond)

- Adhesive bondline quality assurance (post-bond)

...for integration into future adhesive bonding processes

Fig. 1.9 The conception of this book and its chapters 
(e.g. related to surface concentrations). Additionally, relationships were established between the degree of the pre-bond contamination and the observed degradation and the mechanical performance of the resulting adhesive joint. We briefly recall here that substantial progress was made with regard to providing the basis for an integrated approach to the quality assurance of adhesive bonding processes. Against this background, when planning the activities reported in this book, it was of strategic importance that the R\&D work reported here technically and methodically enhances the most promising quality assurance concepts identified within the ENCOMB project and advances them to a TRL of 5-6.

Moreover, we aimed at additionally exploiting the knowledge gained from a series of further aeronautics and NMP projects while interacting with ongoing projects in the field that were in a parallel state of progress, e.g. CleanSky [67] and BOPACS [68]. To accelerate the further development of ENDT technologies for integration into future adhesive bonding process chains as well as allow the assessment of surface quality before bonding and the quality of the finished adhesive joint, the work within the ComBoNDT project was performed alongside test scenarios extracted from the fields of application of manufacturing and repair. Besides their relevance for manufacturing and repair, the outlined test scenarios represented as yet unanswered scientific questions, such as the effect of adherend surface contaminations on the adhesion properties, the overall bonded joint performance and the joint durability. To achieve these goals, we addressed an increase in the degree of automation in connection with a high reproducibility and an adequate measurement speed, an increase in the detection capabilities and the sensitivity of the techniques, a decrease in the costs and an adequate simplicity of handling, in particular with regard to quantifiable results.

Considering all of the above, the ENDT methods identified for further maturation in the frame of the R\&D work reported here were carefully selected with respect to their suitability for the corresponding research approach. The techniques used in the project already existed in the form of laboratory setups, and their applicability was previously tested in the frameworks of other research projects. As summarised for our readers in Table 1.1, feasibility studies were demonstrated in the early phase at the beginning of this decade. To serve the book's scope, as addressed in Sect. 1.3.1 Objectives and Rationale, the selected techniques to be maturated were selected because they had previously demonstrated great applicability and effectiveness. Up to the starting point of our recent R\&D work, the ENDT techniques tested met the basic requirements of a TRL up to 3 or 4 . In some previously conducted projects, feasibility and accuracy were tested for some techniques, which also demonstrated capabilities of detecting and quantifying contamination and indicating failure scenarios of CFRP relevant to aeronautics (ENCOMB, ABiTAS). Among these methods, only the most promising and reliable were chosen for further investigation and improvement. Considering the objectives of this book, their accomplishment was in selecting the most promising techniques developed in previous research, as described above. Hence, the ambitious technical goal of the ComBoNDT project was to transfer the selected technologies from their current TRL state to a higher level (5 or 6). We addressed this goal through activities performed in different fields: 
Table 1.1 Survey of national and international research and innovation activities connected to the ComBoNDT project

\begin{tabular}{|c|c|c|}
\hline $\begin{array}{l}\text { Research and innovation } \\
\text { acronym and status }\end{array}$ & Main topics & Relation to ComBoNDT \\
\hline ABiTAS [69] & $\begin{array}{l}\text { Characterisation of adherend } \\
\text { surfaces with conventional NDT } \\
\text { with the aim of developing a } \\
\text { robust, flexible and economic } \\
\text { process chain for structural } \\
\text { assembly by adhesive bonding. } \\
\text { Surfaces after pretreatment were } \\
\text { screened, tested and optimised }\end{array}$ & $\begin{array}{l}\text { The results of in-process surface } \\
\text { quality control of composite } \\
\text { surfaces with the aim of } \\
\text { achieving an increased TRL } \\
\text { level were applied for } \\
\text { ComBoNDT }\end{array}$ \\
\hline ENCOMB [27] & $\begin{array}{l}\text { Screening of more than } 20 \\
\text { different technologies suitable } \\
\text { for the characterisation of } \\
\text { adherend surfaces and adhesive } \\
\text { bonds, also those with a low } \\
\text { TRL (1-2). Distinct } \\
\text { contamination and degradation } \\
\text { scenarios were introduced to the } \\
\text { samples to test the eligibility and } \\
\text { versatility of the techniques }\end{array}$ & $\begin{array}{l}\text { Much of the knowledge from } \\
\text { ENCOMB regarding suitable, } \\
\text { highly promising NDT for the } \\
\text { development of ENDT was } \\
\text { transferred to ComBoNDT. The } \\
\text { ENCOMB project finished in } \\
\text { April 2014, so the full benefit of } \\
\text { its results provided a foundation } \\
\text { for ComBoNDT }\end{array}$ \\
\hline CleanSky [67] & $\begin{array}{l}\text { The influence of composite } \\
\text { surface properties on bond } \\
\text { durability in repair applications } \\
\text { was studied. The pre-bond } \\
\text { inspection of surfaces was a task } \\
\text { in this context }\end{array}$ & $\begin{array}{l}\text { The studies within ComBoNDT } \\
\text { went beyond the work carried } \\
\text { out in CleanSky, especially } \\
\text { concerning the characterisation } \\
\text { of adhesives and the testing of } \\
\text { adhesive bonds by ENDT }\end{array}$ \\
\hline BOPACS [68] & $\begin{array}{l}\text { The aim of BOPACS was the } \\
\text { weight reduction of primary } \\
\text { aircraft structures by developing } \\
\text { boltless adhesively bonded } \\
\text { joints. The focus lay on the } \\
\text { understanding of crack growth } \\
\text { and debonding expansion } \\
\text { mechanisms in adhesive joints } \\
\text { with an aim of developing } \\
\text { specific design features capable } \\
\text { of preventing crack growth }\end{array}$ & $\begin{array}{l}\text { Some partners from BOPACS } \\
\text { were also members of the } \\
\text { ComBoNDT consortium } \\
\text { (Fraunhofer IFAM, Airbus } \\
\text { Group, LTSM University of } \\
\text { Patras). Thus, it was ensured } \\
\text { that the findings within } \\
\text { BOPACS were implemented in } \\
\text { ComBoNDT }\end{array}$ \\
\hline
\end{tabular}

- The first step included the test scenarios for the project's scope as well as the sample preparation and overview of the sample measurements as previously defined by both the industrial end users and the ground operation service providers.

- The second step included the sample preparation, which complied with the requirements defined by the industrial partners.

- The next step was the characterisation of pre-bond and post-bond quality by reference methods using lab-based analytical methods. (The second and present steps were of paramount importance as a high quality of samples was imperative 
to ensure reproducibility and comparability because the results of the ENDT technologies would be compared to the results of the lab methods).

- The next step included the conduction of mechanical tests to address the influence of contaminants on the bond strength using both established and innovative mechanical tests in samples with different levels of intentionally applied contaminants and, thus, different influences on the bond strength.

- After the completion of the mechanical tests, the next step concerned ENDT for the quality assessment of adherend surfaces (pre-bond inspection). The performance of the ENDT technologies was adapted and optimised regarding their sensitivity to detect the physico-chemical properties of adherend surfaces with multiple pre-bond contaminations as well as their suitability in quantifying the measuring results. This work included the further development of the technologies with regard to sensitivity, reliability, automation and mobility, the performance evaluation within real manufacturing or repair processes, and approaches for industrialisation. Another activity was performed in parallel which dealt with ENDT for adhesive bondline quality assurance (post-bond inspection). Within this activity, the evaluation and development of appropriate technologies with high sensitivity formed the primary interest in order to determine the bondline quality influenced by multiple pre-bond contaminations as well as to quantify the results. The sensibility, reliability, automation and mobility of the techniques were assessed by their implementation in real manufacturing or repair processes.

- A further step was the demonstration of the adapted and improved ENDT techniques in real application environments for both manufacturing and repair in order to reveal their suitability for future use in aeronautical industry applications.

- Another step was the validation and technological assessment of ENDT methods and investigations. In this part, the work was aimed specifically at the comparative evaluation of the produced innovations regarding their suitability for measurements in production or in-service environments through an assessment of their TRL (including simplicity of handling, time for data processing, detection capability, costs, lifetime, etc.), in-line capability, mobility and robustness. This activity also included probability of detection (POD) studies to evaluate the detection performance of each technique. In the frame of validation of the techniques of the project, a round-robin test was used.

- Finally, the broad dissemination and exploitation of the results, in parallel to the protection and safeguarding of the intellectual property rights of the partners involved in the project, was ensured, as the reader may infer from the present book.

- On the way to all these achievements, the overall project management was dedicated to all activities, ensuring efficient project coordination towards achieving the project's objectives.

Following the conceptualisation and throughout the course of our R\&D work, distinct levels of pre-bond contamination, the influence of which was addressed via mechanical testing, needed to be previously detected and preferably discriminated by the ENDT techniques and quantitative evaluation of the quality-related data. 
Table 1.2 Approaches pursued within this book, characterised by different types of test scenarios addressing the fields of application for in-plant manufacturing and in-service repair based on adhesive bonding

\begin{tabular}{|c|c|c|}
\hline \multirow{2}{*}{$\begin{array}{l}\text { Sample } \\
\text { geometry and } \\
\text { surface state }\end{array}$} & \multicolumn{2}{|l|}{ Fields of applications investigated } \\
\hline & $\begin{array}{l}\text { ENDT for pre-bond (a) and post-bond } \\
\text { (b) quality assurance for manufacturing }\end{array}$ & $\begin{array}{l}\text { ENDT for pre-bond (a) and post-bond } \\
\text { (b) quality assurance for repair }\end{array}$ \\
\hline $\begin{array}{l}\text { - Test } \\
\text { coupons } \\
\text { (flat } \\
\text { surface) } \\
\text { - Multiple } \\
\text { contaminant }\end{array}$ & 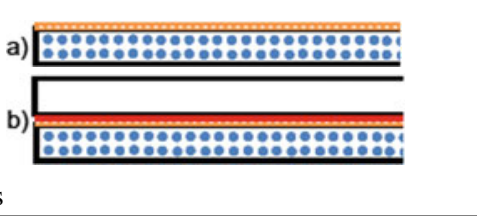 & 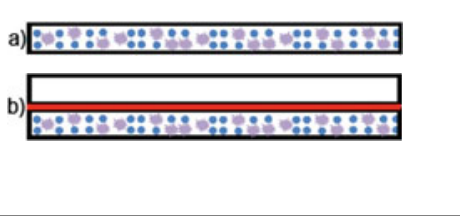 \\
\hline \multirow[t]{2}{*}{$\begin{array}{l}\text { - Pilot } \\
\text { samples } \\
\text { (complex } \\
\text { geometry) } \\
\text { - Multiple } \\
\text { contaminant }\end{array}$} & :0:8:8:8:8:8: & a) \\
\hline & $\begin{array}{l}\text { - moisture contamination } \\
\text { release agent contamination }\end{array}$ & $\begin{array}{l}\text { Skydrol } \odot \text { contamination } \\
\text { adhesive bondline }\end{array}$ \\
\hline
\end{tabular}

From a manufacturing perspective, in the production scenarios, a contamination of adherend surfaces with, e.g. release agent and moisture was considered to be highly relevant. A variation due to the impact of moisture, hydraulic fluids such as Skydrol ${ }^{\odot}$, kerosene or de-icing fluid may also occur during aircraft operation. Therefore, corresponding exposures were taken into consideration for the repair test scenarios. These scenarios with contaminations, relevant for the respective field of application from manufacturing and repair, were applied to samples with increasing geometric complexity to mimic technologically relevant situations, as displayed in Table 1.2.

\subsubsection{Aims and Key Aspects}

The exploitation of lightweight CFRP materials for further use in aeronautic applications presupposes adhesive bonding as a very appropriate joining technology for load-critical primary structures [62] and the compliance with the appropriate certification (e.g. by the European Aviation Safety Agency, EASA). Due to the absence of an adequate quality assurance concept which can guarantee the safety of adhesively bonded joints and enable a corresponding certification, the previously mentioned exploitation was not possible. Such a quality assurance concept for adherend surfaces and the contacting bondline is crucial for load-critical bonds and must be effective. However, quality assessment exclusively involving the already existing NDT 
testing methods is not considered sufficiently reliable [70]. As the major part (80$90 \%$ ) of any inspection is performed visually, it is very important for advances in quality inspection that the technologically relevant effects of deviations from qualified procedures, e.g. damage, which are not accessible to human sensory perception can be sensitively detected and revealed in-process. Taking this proposition into account, a number of research projects targeted addressing and developing innovative NDT technologies in laboratory environments. These trendsetting technologies should be able to monitor the adherend surfaces and bonded joints and assess their quality-relevant features which may be affected by surface contaminations or manifest in kissing bonds. To this end, the effect of single contaminants was assessed for simple sample geometries. Nevertheless, these NDT techniques had not been tested in scenarios of multiple contaminations or on realistic three-dimensional and complex geometries.

In the frame of this book, we will highlight these tests comprising tools and procedures for in-process quality assessment using pilot samples charged with multiple contaminants; moreover, the techniques' operation and their application are demonstrated on real manufacturing and repair components. The aim is to prove their suitability and reliability for surface and bondline quality detection and compilation. This work is performed with the ultimate goal of the certification of CFRPs as the primary material in critical structural applications. Another issue is the maturation of innovative NDT methods in terms of the TRL, considering the fact that these basically had only been tested in a laboratory environment. To this end, our R\&D work aimed not only at the increment of their TRL but also at building up a catalogue of criteria for an assessment of ENDT techniques applicable to adherend surfaces and bondlines of load-critical CFRP structures. In addition, within the developed concept of assessing technologically relevant quality-related features, mechanical tests of the resulting bonded joints were highlighted as necessary in order to determine the influence of contaminants up to a contamination level that shows a risk. Considering that the existing standardised methods entail a high cost and work effort, focused destructive tests providing selected specific bond strength parameters and statistics were performed. Despite this issue, the mechanical tests chosen and performed were those that appeared to be the most time and work-efficient, in addition to the most innovative ones (i.e. the centrifuge test).

\section{Mechanical testing}

More precisely, when evaluating the influence of the intentionally varied adherend surface state (clean, single or multiple contaminations) on the mechanical properties, established standardised mechanical tests like mode-I, mode-II and mixed-mode fracture toughness tests are widely used. These tests are time- and cost-consuming due to complex sample preparation, destructive single-sample testing and manual evaluation of the mechanical load and of the two obtained fracture surfaces. These limitations for standardised testing have been recognised in many previous research projects such as ENCOMB and ABiTAS. Although these significant standardised mechanical tests were knowingly chosen to be performed in the frame of our R\&D work, we additionally used a new multiple sample test (centrifuge-testing) because it 
was ascribed great potential to overcome the limitations of standardised tests within the BOPACS project. With this novel centrifuge test, up to eight samples can be measured within five minutes. The measured mechanical properties have previously shown accuracy with a very good precision and reproducibility. The novel testing is cost-efficient, fast and reliable, and it indeed increased the information value of mechanical testing compared to the results from standardised mechanical tests.

\section{TRL assessment}

TRLs are commonly used to evaluate the maturity of technologies (e.g. NDT techniques, pre-treatments) regarding their degree of development and applicability in industrial processes. There are several definitions of TRLs, e.g. from the EC for H2020, from the U.S. Department of Defense, NASA and ESA; however, these definitions are more general without including specific criteria for special applications. With regard to the fields of application addressed within this book (i.e. manufacturing and repair), different criteria are relevant for TRL assessment.

Establishing a satisfactory catalogue of criteria for the assessment of TRL for preand post-bond ENDT technologies to be used in the fields of manufacturing and repair for CFRP primary structures is a major challenge that will be elaborately assessed in this book, especially by our co-authors from industrial consortium partners experienced in manufacturing and ground services. They worked on the creation of a catalogue of requirements tailored specifically for the TRL assessment for ENDT in the chosen fields of application. With this catalogue, a distinct determination of TRL will be possible for the specific fields of application investigated within this book. With a distinct and comprehensive TRL assessment, the comparability of the test methods and the TRL improvements achieved within the project were measurable and became very clear. TRL assessment was performed according to this catalogue at the beginning (initial TRL) of our R\&D work and at its end (final TRL achieved).

\section{Monitoring of adherend surface conditions and bondline quality by in-line techniques}

During the manufacturing and repair processes of CFRP materials, the quality assurance of adherend surfaces has, up to now, been performed using the water-break test for the large-area inspection of wettability properties [71]. Hydrophobic surface areas (originating from residues of, e.g. release agents or lubricants) are detected by changes in the wetting behaviour. The test is performed manually and its evaluation is done visually with an individual pair of human eyes and is, therefore, is subjective and error-prone. The water-break test is followed by time- and workconsuming drying and cleaning steps for the investigated specimens. Furthermore, water-soluble contaminants cannot be detected by this procedure (though they might have been present in the non-investigated surface regions as well), which is another disadvantage. For the inspection of small areas, contact angle or also surface energy measurements and test-inks are commonly employed. These tests only allow a monitoring of very small areas of the sample and require an additional cleaning step before bonding, and it is even recommended that they be performed adjacent to the intended bonding area, not inside it. Figure 1.10 shows a demonstrative example of applying the water-break test (left) and an ultrasonic picture of a delamination in CFRP (right). 


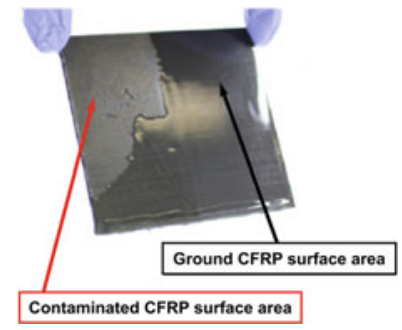

Water-break test

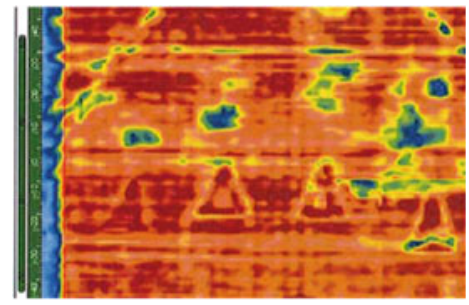

Ultrasonic picture of delamination in CFRP

Fig. 1.10 The water-break test (left) and a state-of-the-art ultrasonic picture of the delamination (right) of CFRP

Adhesively bonded structures are also inspected by means of conventional NDT, e.g. visual inspection and audible sonic testing (tap test), to detect damages by comparing the local perception to one obtained in the vicinity or with a reference specimen. These tests are performed manually and are therefore subjective as the results depend to a great extent on the concentration, skills and experience of the operator. Furthermore, damage that is non-perceivable by unaided human senses will not be detected. More complex measuring techniques like ultrasound, thermography, shearography and radiography often need well-trained personnel and require timeconsuming spectrum evaluation steps. Current conventional NDT techniques allow the detection of defects like pores, resin starvation/richness, wrinkles, discolouration (e.g. due to overheating, lightning strike), disbonding and delaminations in the joint area [72]. In addition, for ultrasound testing a couplant material such as water must be applied between the sensor and the investigated surface. Expensive re-drying and cleaning processes are therefore necessary and only single-point measurements are possible [70]. The state-of-the-art devices do not provide the necessary information for the quality assurance of adhesive joints and still have many disadvantages and shortcomings. The aforementioned state-of-the-art methods and devices are furthermore limited by the fact that defects like kissing bonds and a weakening of bonded joints cannot be detected.

Based on the results obtained within former research activities and extracted from a literature review, we carefully selected NDT technologies based on their state-ofthe-art performance for further investigation in order to address these limitations. The identified technologies proved their capability to successfully detect contaminants relevant in aircraft manufacturing and in-service repair as well as to assess adhesive bond quality. All of the selected NDT techniques had the potential to reach a TRL high enough for their use in manufacturing and repair environments in order to provide quality control systems for surface and bondline inspection. The ENDT technologies that are relevant for the R\&D work within this book are listed in Table 1.3 together with their main limitations in the early 2010s and the progress that was aspired to be realised within the project. 


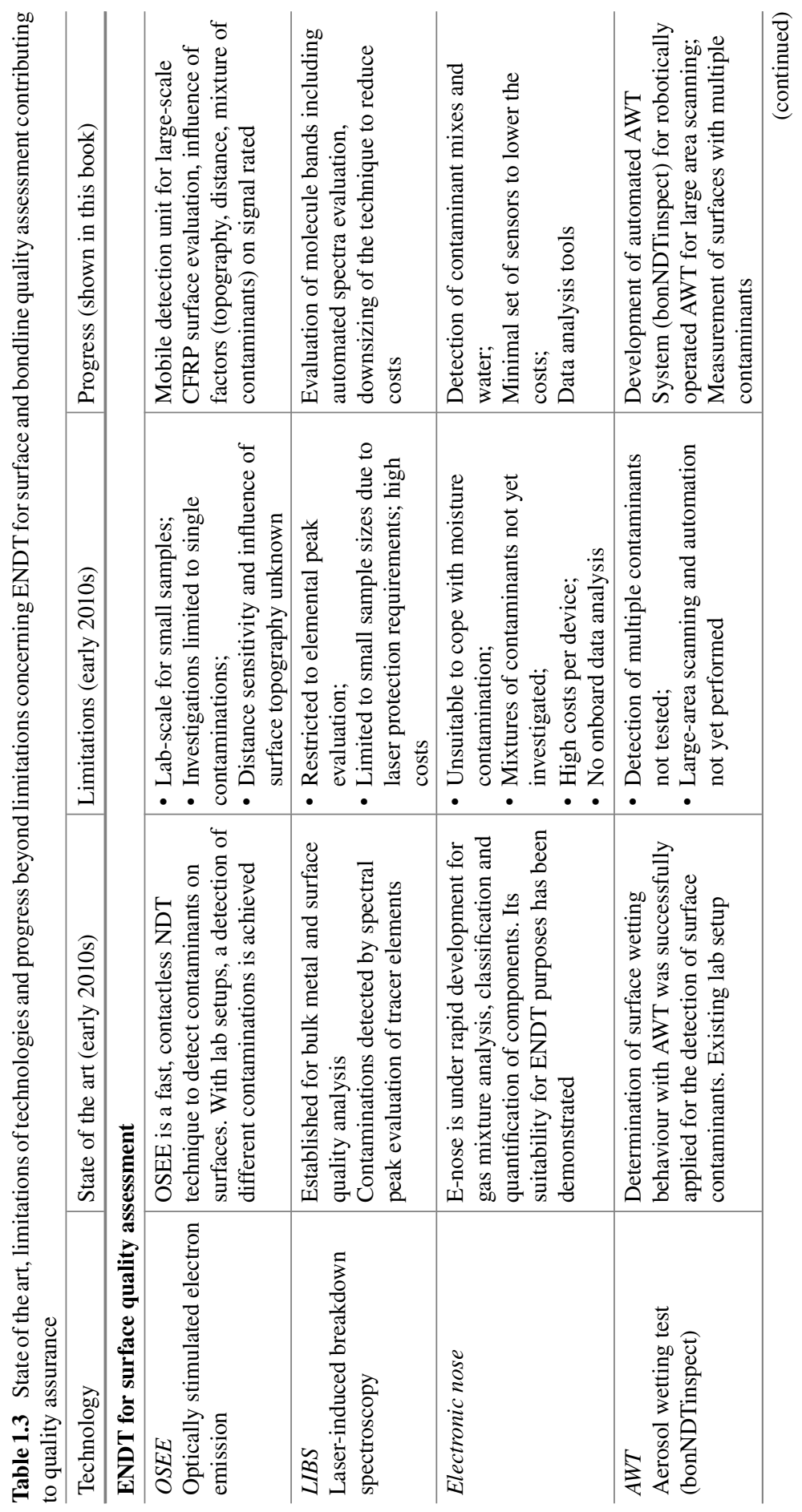




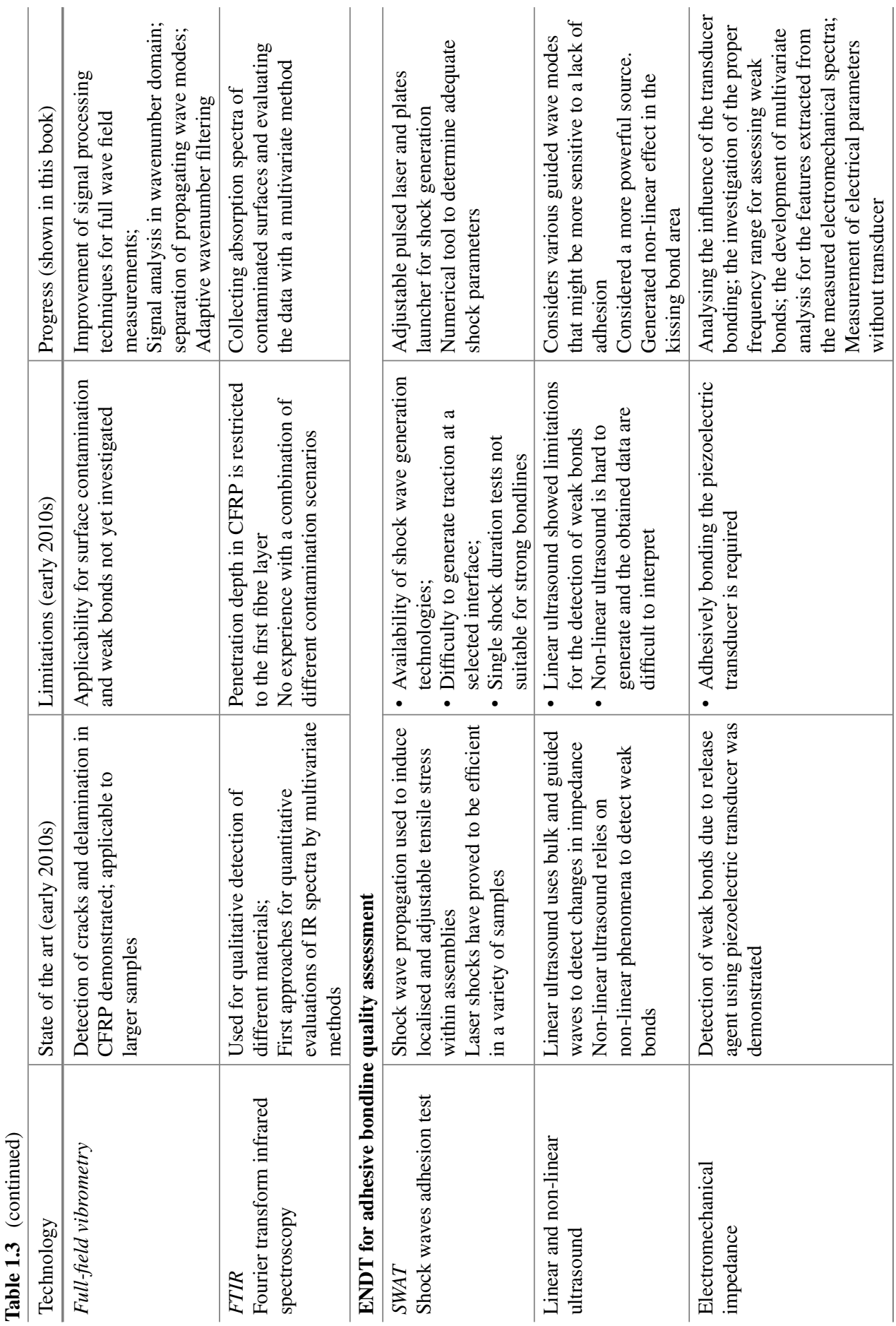




\subsubsection{Impacts and Contributions}

The use of CFRP as an innovative material for aircraft design has increased immensely within the few last years [22, 29, 62] (the Airbus A350 XWB is composed of up to $53 \%$ CFRP), leading to an increasing demand for both high quality and quantity of composite material and composite joints, accompanied by lower costs. Adhesive bonding as a joining technology can enable the use of the full potential of CFRP as a lightweight material for aircraft design and is already used for joining many CFRP-based aircraft parts. Admittedly, adhesive bonding has thus far not been applied for load-critical CFRP primary aircraft structures. However, it is highly desirable to facilitate adhesive bonding as a joining technology for load-critical primary structures because adhesive bonding and adhesive joints possess numerous advantages over other processes: homogeneous stress distribution, full automation capability, lightweight design, strong and even complex structure design, capability of joining two distinct materials, interesting properties in electrolytic and corrosion protection and finally high fatigue resistance furnishing a longer service lifetime compared to mechanically bonded structures.

Most of the aircraft produced nowadays contain a high amount of CFRP material and therefore require the adhesive bonding of CFRP in manufacturing, maintenance and repair [29]. From our point of view, this further emphasises the need for complete and reliable quality assurance concepts based on appropriate and resilient ENDT techniques for quality assessment. This large number of affected industry sectors leads to the huge impact of the findings and achievements reported in this book. The provision of quality assurance concepts (using ENDT techniques) for load-critical primary structures will allow the increased and optimal use of CFRP and the replacement of metallic assembly concepts resulting in weight, time and cost savings for the aeronautic and all related industries. Moreover, it directly supports the certification and continued airworthiness of repaired CFRP structures. The R\&D work presented in this book is clearly aligned with this objective through the maturation, improvement and adaptation of ENDT technologies for the characterisation of, on the one hand, the CFRP adherend surface state before bonding (pre-bond) and, on the other hand, the CFRP bonded structures (post-bond) in order to establish complete and process-comprehensive quality assurance concepts. We consider this the key to overcoming current limitations for the use of CFRP in aeronautical applications.

We expect that the innovations reported in this book will result in substantial socio-economic, technical and environmental impacts. Firstly, an impact will be achieved by reinforcing the competitiveness of Europe's aircraft industry and European aircraft operators by assisting the development of high technology SMEs and by accomplishing an increment of safety resulting from more reliable components and processes, which will strengthen and augment the reputation of the European aviation and aeronautics industry. Secondly, our contributions will bring about an integration of innovative materials in aeronautics as well as automated measuring processes in combination with strong signal evaluation processes that will provide surface and structural health data and contribute significantly to the reduction of human 
errors; therefore, an increment of safety will result from more reliable components and processes, weight savings of aircraft will be facilitated, and an improvement of the safety and operational capabilities of aircraft will ensue. Thirdly, a significant reduction of energy for the performance of the inspection, for the manufacturing of replacement parts and for the manufacturing of primary structures will be feasible, as will a reduction of scrapping rates during manufacture or repair and a weight reduction of aircraft.

Finally, we would like to highlight and acknowledge again the invaluable contributions resulting from the strong cooperation within the ComBoNDT consortium and promoted by the dedicated project management. The consortium consisted of eleven partners, including major European aerospace companies as well as highlevel research organisations and universities experienced in aeronautics research and development. The project team consisted of aircraft manufacturers (Airbus Group; AERNNOVA Composites Illescas S.A.) in close collaboration with the research partners Fraunhofer Institute for Manufacturing Technology and Advanced Materials IFAM (IFAM), Instytut Maszyn Przepływowych im. Roberta Szewalskiego Polskiej Akademii Nauk (IMP-PAN), Centre National De La Recherche Scientifique (CNRS), Agenzia nazionale per le nuove tecnologie, l'energia e lo sviluppo economico sostenible (ENEA), University of Patras (LTSM-UPAT), and the Commissariat à l'énergie atomique et aux énergies alternatives (CEA), together with the small and medium-sized enterprises EASN Technology Innovation Services BVBA (EASN), GMI Aero SAS (GMI), and Automation W + R GmbH (AWR).

\subsection{Synopsis}

In this chapter, we presented a short introduction to ENDT and quality assessment in adhesive bonding processes relevant to the manufacture or repair of composite structures. We highlighted their relevance as field-level sensing systems for industrial automation and also for literally safeguarding quality in various steps of adhesive bonding processes. They will essentially contribute to quality assurance and optimisation within a manufacturing technology that we consider the most auspicious of the twenty-first century for innovations in joining functional or lightweight materials and components.

Based on a fast, firm and formal description of adhesive bonding processes and conferred to quality assurance, we determined that the analytical requirement for a monitoring process is far less complex than predicting any property of the ultimately manufactured adhesive joint, like the initial (or even final) strength or fracture toughness, which is often set as a fundamental design specification. Rather, indicating any deviations from a known, understood and qualified procedure will facilitate the timely, purposeful and precise amendments for achieving and maintaining the technologically relevant material and environment states following the requirements. All things considered, the documented compliance with documented procedures 
contributes to risk reduction and safety, while also safeguarding the economic value and social acceptance of the processes and products.

We have detailed that, especially in the past decade, the monitoring of qualityrelevant operand features which are characteristic for the adherend and adhesive materials has caught up with the virtually established methods and instrumentation for controlling the acting operators, i.e. process factors which effectuate changes of the operand features. A major contribution to this advance in operand QA was traced back to recent developments of ENDT tools, e.g. in the European joint research projects ENCOMB and ComBoNDT. Moreover, we explicated the layout of a concept that was developed in these interdisciplinary and applied research projects. This is based on an interdisciplinary, comprehensive and forthright analysis and a description of the supposedly controlled production environment and monitoring of deviations or events which occur when quality-relevant operator-related factors are intentionally and quantitatively altered in technologically relevant increments.

We hope that we have intrigued our readers, and we will animate this concept for ENDT and quality assessment in adhesive bonding within the subsequent chapters of this book.

\section{References}

1. Regert M (2004) Investigating the history of prehistoric glues by gas chromatography-mass spectrometry. J Sep Sci 27:244-254. https://doi.org/10.1002/jssc.200301608

2. Conard NJ, Malina M, Münzel SC (2009) New flutes document the earliest musical tradition in southwestern Germany. Nature 460:737-740. https://doi.org/10.1038/nature08169

3. Gegner J (2008) Klebtechnik - multifunktionales Fügen für den nachhaltigen Werkstoffeinsatz im 21. Jahrhundert. Mat.-wiss u Werkstofftech 39:33-44. https://doi.org/10.1002/mawe.200 700228

4. Regert M, Rodet-Belarbi I, Mazuy A et al (2019) Birch-bark tar in the Roman world: the persistence of an ancient craft tradition? Antiquity 93:1553-1568. https://doi.org/10.15184/ aqy. 2019.167

5. Trehub SE, Becker J, Morley I (2015) Cross-cultural perspectives on music and musicality. Philos Trans R Soc Lond B Biol Sci 370:20140096. https://doi.org/10.1098/rstb.2014.0096

6. Conard NJ, Malina M (2008) New evidence for the origins of music from the caves of the Swabian Jura. In Both AA, Eichmann R, Hickmann E, Koch L-Ch (Eds), Challenges and objectives in music archaeology. Studien zur Musikarchäologie VI, Orient-Archäologie 22:1322, Verlag Marie Leidorf GmbH, Rahden, Germany, ISBN 978-3-896-46652-5

7. Osipowicz G (ed) (2014) Kowal 14: Sepulchral and ritual place of people representing the Globular Amphora Culture. Wydawnictwo Naukowe Uniwersytetu Mikołaja Kopernika, Toruń, ISBN 978-83-231-3328-5

8. Rao H, Yang Y, Abuduresule I et al (2015) Proteomic identification of adhesive on a bone sculpture-inlaid wooden artifact from the Xiaohe Cemetery, Xinjiang, China. J Archaeol Sci 53:148-155. https://doi.org/10.1016/j.jas.2014.10.010

9. Brockmann W, Geiß PL, Klingen J, Schröder KB (2008) Adhesive bonding: materials, applications and technology. Wiley-VCH, Weinheim, ISBN 978-3-527-62393-8

10. Kozowyk PRB, Soressi M, Pomstra D et al (2017) Experimental methods for the Palaeolithic dry distillation of birch bark: implications for the origin and development of Neandertal adhesive technology. Sci Rep 7:8033. https://doi.org/10.1038/s41598-017-08106-7 
11. Gross A, Lohse H (2015) Quality assurance in adhesive bonding technology-new DIN 2304 standard and its use in practice. Adhes Adhes Sealants 12-17. https://doi.org/10.1007/s35784015-0534-4

12. Reiling JM, Middendorf P, Sindel M (2015) Quality assurance of adhesive processes in the body shop. In: Bargende M, Reuss H-C, Wiedemann J (eds) 15. Internationales Stuttgarter Symposium. Springer Fachmedien Wiesbaden, Wiesbaden, pp 1421-1431

13. Paul F (2017) Adhesive bonding roadmap-increasing trust in adhesives. DECHEMA, Frankfurt am Main

14. Encinas N, Oakley BR, Belcher MA et al (2014) Surface modification of aircraft used composites for adhesive bonding. Int J Adhes Adhes 50:157-163. https://doi.org/10.1016/j.ijadhadh. 2014.01.004

15. Ledesma RI, Palmieri FL, Yost WT et al (2017) Surface monitoring of CFRP structures for adhesive bonding, $40^{\text {th }}$ Annual Meeting, The Adhesion Society, St. Petersburg, Florida, USA

16. Kraft A, Brune K (2017) Assured use of release agents and adhesives in the same production process. Lightweight des Worldw 10:40-43. https://doi.org/10.1007/s41777-017-0013-5

17. Konstantopoulos S, Fauster E, Schledjewski R (2014) Monitoring the production of FRP composites: a review of in-line sensing methods. Express Polym Lett 8:823-840. https://doi. org/10.3144/expresspolymlett.2014.84

18. Hübner M, Lang W, Dumstorff G (2017) Surface integrated printed interdigital structure for process monitoring the curing of an adhesive joint. Proceedings 1:631. https://doi.org/10.3390/ proceedings 1040631

19. Soldatos J, Gusmeroli S, Malo P, Di Orio D (2016) Internet of Things applications in future manufacturing. In: Vermesan O, Friess P (eds) Digitising the industry: Internet of Things connecting the physical, digital and virtual worlds. River Publishers, Gistrup, Denmark, ISBN 978-8-793-37981-7

20. de Baas AF (2017) Data and documentation terminology, classification and ontology. Common terminology and classification, efficient communication. https://emmc.info/wp-content/upl oads/2017/12/EMMC_IntOp2017_Cambridge_deBaas_EC.pdf

21. Gellrich A, Lunkwitz D, Dennert A et al (2012) Rule-driven manufacturing control based on ontologies. In: Proceedings of 2012 IEEE 17th international conference on emerging technologies \& factory automation (ETFA 2012). IEEE, pp 1-8. https://doi.org/10.1109/ETFA.2012. 6489545

22. Ullmann T, Schmidt T, Hoffmann S et al (2010) In-line quality assurance for the manufacturing of carbon fiber reinforced aircraft structures. In: NDT.net Issue: 2011-03, 2nd Int. Symposium on NDT in aerospace 2010-Tu.1.A.4

23. Dahmen T, Trampert P, Boughorbel F et al (2019) Digital reality: a model-based approach to supervised learning from synthetic data. AI Perspect 1. https://doi.org/10.1186/s42467-0190002-0

24. Gifford C, Daff D (2017) ISA-95 evolves to support smart manufacturing and IIoT-New challenges and opportunities for manufacturing technologies and standards across industries, InTech, November/December

25. Feng SC, Bernstein WZ, Hedberg T et al (2017) Towards knowledge management for smart manufacturing. J Comput Inf Sci Eng 17. https://doi.org/10.1115/1.4037178

26. Katnam KB, da Silva LFM, Young TM (2013) Bonded repair of composite aircraft structures: a review of scientific challenges and opportunities. Prog Aerosp Sci 61:26-42. https://doi.org/ 10.1016/j.paerosci.2013.03.003

27. ENCOMB "Extended Non-Destructive Testing of Composite Bonds" (2010-2014) Project funded from the European Union's Seventh Framework Programme under grant agreement No 266226

28. ComBoNDT "Quality assurance concepts for adhesive bonding of aircraft composite structures by advanced NDT" (2015-2018) Project funded from the European Union's Horizon 2020 research and innovation programme under grant agreement No 636494

29. Kanterakis G, Chemama R, Kitsianos K (2020) Bonded repair of composite structures. In: Pantelakis S, Tserpes K (eds) Revolutionizing aircraft materials and processes. Springer Nature, [S.1.], pp 359-392. https://doi.org/10.1007/978-3-030-35346-9_13 
30. Light GM, Kwun H (1989) Nondestructive evaluation of adhesive bond quality. State-of-theArt Review: SwRI Project 17-7958-838, Nondestructive Testing Information Analysis Center San Antonio, Texas, USA

31. Mattmann I (2017) Modellintegrierte Produkt- und Prozessentwicklung. Springer Fachmedien Wiesbaden GmbH, Wiesbaden, Germany, ISBN 978-3-658-19408-6

32. Espie AW (1998) Quality assurance in adhesive technology: EUREKA Project EU716. Abington Publishing, Cambridge

33. DIN EN ISO 9000:2015-11 (2015) Qualitätsmanagementsysteme - Grundlagen und Begriffe (ISO 9000:2015): Deutsche und Englische Fassung EN ISO 9000:2015(DIN EN ISO 9000:2015-11)

34. Markus S, Wilken R, Dieckhoff S (2006) Fehlervermeidung durch Inline-Monitoring des Oberflächenzustandes. Adhaes Kleb Dicht 50:20-22. https://doi.org/10.1007/BF03253336

35. DIN 2304-1:2016-03 (2016) Adhesive bonding technology—quality requirements for adhesive bonding processes: Part 1: Adhesive bonding process chain (DIN 2304-1:2016-03)

36. Allotrope Foundation (2020) Data Standard I Allotrope Foundation. https://www.allotrope.org/

37. Qin SJ, Zheng Y (2013) Quality-relevant and process-relevant fault monitoring with concurrent projection to latent structures. AIChE J 59:496-504. https://doi.org/10.1002/aic.13959

38. Peng K, Zhang K, You B et al (2016) A quality-based nonlinear fault diagnosis framework focusing on industrial multimode batch processes. IEEE Trans Ind Electron 1. https://doi.org/ 10.1109/TIE.2016.2520906

39. Huang J, Yan X (2017) Quality relevant and independent two block monitoring based on mutual information and KPCA. IEEE Trans Ind Electron 64:6518-6527. https://doi.org/10.1109/TIE. 2017.2682012

40. Huang J, Yan X (2018) Relevant and independent multi-block approach for plant-wide process and quality-related monitoring based on KPCA and SVDD. ISA Trans 73:257-267. https:// doi.org/10.1016/j.isatra.2018.01.003

41. Moyne J, Iskandar J (2017) Big data analytics for smart manufacturing: case studies in semiconductor manufacturing. Processes 5:39. https://doi.org/10.3390/pr5030039

42. Berger D, Zaiß M, Lanza G et al (2018) Predictive quality control of hybrid metal-CFRP components using information fusion. Prod Eng Res Devel 12:161-172. https://doi.org/10. 1007/s11740-018-0816-1

43. Wassink CHP (2012) Innovation in non destructive testing. Dissertation, TU Delft

44. Custódio J, Cabral-Fonseca S (2013) Advanced fibre-reinforced polymer (FRP) composites for the rehabilitation of timber and concrete structures: assessing strength and durability. In: Bai J (ed) Advanced fibre-reinforced polymer (FRP) composites for structural applications. Elsevier Science, Burlington, pp 814-882. https://doi.org/10.1533/9780857098641.4.814

45. DIN 6701-2:2015-12 (2015) Adhesive bonding of railway vehicles and parts-Part 2: Qualification of manufacturer of adhesive bonded materials(DIN 6701-2:2015-12)

46. Michaloudaki M (2005) An approach to quality assurance of structural adhesive joints. PhD thesis, Technical University Munich

47. Davis M (2004) Best practice in adhesive bonding. https://www.niar.wichita.edu/niarworks hops/Portals/0/BestPracticesinAdhesiveBondingMaxDavis.pdf

48. Niermann D, Gross A, Brede M et al (2005) Quality assurance in adhesive bonding technology. Adhaes Kleb Dicht 30-32

49. Niermann D, Gross A, Brede Met al (2005) Quality assurance in adhesion (Part 1): Construction phase-which general valid quality assurance measures apply to be observed? Adhaes Kleb Dicht 49:36-38

50. Niermann D, Gross A, Brede M et al (2005) Quality assurance in adhesive technology (Part 2): Production phase. Adhaes Kleb Dicht 49:28-32

51. Pirolini A (2014) Quality assurance trends in the automotive industry: an interview with Alex Koprivc. AZO Materials. https://www.azom.com/article.aspx?ArticleID=11065

52. Flämmich M, Herdin H, Kunz U, Mannschreck K, Schulze L, Straub R (2020) Guidelines for Quality Assuring Process Management in Parts Cleaning. Fachverband Industrielle Teilereinigung e.V. (FiT) 
53. Ebnesajjad S, Landrock AH (2015) Chapter 13-Quality control. In: Ebnesajjad S, Landrock AH (eds) Adhesives technology handbook (Third Edition) William Andrew Pub, Norwich, NY, pp 353-374. https://doi.org/10.1016/B978-0-323-35595-7.00013-9

54. Messler SW (1993) Joining of advanced materials. Elsevier Science, Burlington

55. Breuer F, Muckel P, Dieris B (2018) Reflexive Grounded Theory: Eine Einführung für die Forschungspraxis, 3., vollständig überarbeitete und erweiterte Auflage. Lehrbuch. Springer, Wiesbaden

56. Nielsen J (1994) 10 Usability heuristics for user interface design. https://www.nngroup.com/ articles/ten-usability-heuristics/

57. Kleining G, Witt H (2000) The qualitative heuristic approach: a methodology for discovery in psychology and the social sciences. Rediscovering the method of introspection as an example. Forum: Qualitative Social Research 1(1), Art. 13. http://nbn-resolving.de/urn:nbn:de:0114-fqs 0001136

58. Budhe S, Banea MD, de Barros S et al (2017) An updated review of adhesively bonded joints in composite materials. Int J Adhes Adhes 72:30-42. https://doi.org/10.1016/j.ijadhadh.2016. 10.010

59. Kreling S, Blass D, Wilken R et al (2017) Sauber und prozesssicher vorbehandeln - Teil 1: [Pretreating cleanly and in a process-reliable manner - PART 1]. Adhaes Kleb Dicht 61:18-23

60. Kreling S, Blass D, Wilken R et al (2017) Sauber und prozesssicher vorbehandeln - PART 2: [Pretreating cleanly and in a process-reliable manner - PART 2]. Adhaes Kleb Dicht 24-28

61. Halliwell S, Repair of fibre reinforced polymer (FRP) structures. National composites network best practice guide

62. Tserpes K (2020) Adhesive bonding of aircraft structures. In: Pantelakis S, Tserpes K (eds) Revolutionizing aircraft materials and processes. Springer Nature, [S.1.], pp 337-357. https:// doi.org/10.1007/978-3-030-35346-9_12

63. Tornow C, Brune K, Noeske M (2014) Verfahren und Vorrichtung zur Bestimmung einer Oberflächengüte (DE102014209862A1)

64. Jeenjitkaew C, Guild FJ (2017) The analysis of kissing bonds in adhesive joints. Int J Adhes Adhes 75:101-107. https://doi.org/10.1016/j.ijadhadh.2017.02.019

65. Acare (2020) Acare-Advisory Council for Aviation Research and Innovation in Europe. https://www.acare4europe.org/

66. EASA (2010) Composite Aircraft Structure: Annex II to ED Decision 2010/003/R of 19/07/2010(AMC 20-29). https://www.easa.europa.eu/sites/default/files/dfu/Annex\%20II\% 20-\%20AMC\%2020-29.pdf

67. Clean Sky (2020) Welcome to the Clean Sky I Clean Sky. https://www.cleansky.eu/

68. BOPACS "Boltless assembling Of Primary Aerospace Composite Structures" (2012 - 2016) Project funded from the European Union's FP7-TRANSPORT programme under grant agreement No 314180. https://cordis.europa.eu/project/id/314180/de

69. ABiTAS "Advanced Bonding Technologies for Aircraft Structure" (2006 - 2010) Project funded from the European Union's FP6-AEROSPACE programme under grant agreement No 30996

70. Esquivel O, Seibold RW (2004) Capabilities and Limitations of Nondestructive Evaluation Methods for Inspecting Components Beneath Thermal Protection Systems. AEROSPACE REPORT NO. ATR-2004(5081)-1, Cambridge, MA 02142-1093

71. ASTM F22 - 13: Standard Test Method for Hydrophobic Surface Films by the Water-Break Test. In: ASTM Volume 15.03 Space Simulation; Aerospace and Aircraft; Composite Materials. ASTM International

72. Federal Aviation Administration (2017) AMT Airframe Handbook Volume 1 (Full Version) (Faa-H-8083-31). By: Federal Aviation Administration. Aviation Maintenance Technician Handbook - Airframe, vol 1. Createspace Independent Publishing Platform 
Open Access This chapter is licensed under the terms of the Creative Commons Attribution 4.0 International License (http://creativecommons.org/licenses/by/4.0/), which permits use, sharing, adaptation, distribution and reproduction in any medium or format, as long as you give appropriate credit to the original author(s) and the source, provide a link to the Creative Commons license and indicate if changes were made.

The images or other third party material in this chapter are included in the chapter's Creative Commons license, unless indicated otherwise in a credit line to the material. If material is not included in the chapter's Creative Commons license and your intended use is not permitted by statutory regulation or exceeds the permitted use, you will need to obtain permission directly from the copyright holder.

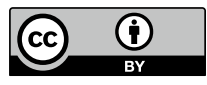

